\title{
The geology of the Marcia quadrangle of asteroid Vesta: Assessing the effects of large, young craters
}

\author{
David A. Williams ${ }^{\mathrm{a}, *}$, Brett W. Denevi ${ }^{\mathrm{b}}$, David W. Mittlefehldt ${ }^{\mathrm{c}}$, Scott C. Mest ${ }^{\mathrm{d}}$, Paul M. Schenk ${ }^{\mathrm{e}}$, \\ R. Aileen Yingst ${ }^{\mathrm{d}}$, Debra L. Buczkowski ${ }^{\mathrm{b}}$, Jennifer E.C. Scully ${ }^{\mathrm{f}}$, W. Brent Garry ${ }^{\mathrm{g}}$, Thomas B. McCord ${ }^{\mathrm{h}}$, \\ Jean-Phillipe Combe ${ }^{\mathrm{h}}$, Ralf Jaumann ${ }^{\mathrm{i}}$, Carle M. Pieters ${ }^{\mathrm{j}}$, Andreas Nathues ${ }^{\mathrm{k}}$, Lucille Le Corre ${ }^{\mathrm{k}}$, \\ Martin Hoffmann ${ }^{k}$, Vishnu Reddy ${ }^{k}$, Michael Schäfer ${ }^{k}$, Thomas Roatsch ${ }^{\mathrm{i}}$, Frank Preusker ${ }^{\mathrm{i}}$, \\ Simone Marchi ${ }^{1}$, Thomas Kneissl ${ }^{\mathrm{m}}$, Nico Schmedemann ${ }^{\mathrm{m}}$, Gerhard Neukum ${ }^{\mathrm{m}}$, Harald Hiesinger ${ }^{\mathrm{n}}$, \\ Maria Cristina De Sanctis ${ }^{\circ}$, Eleonora Ammannito ${ }^{\circ}$, Alessandro Frigeri ${ }^{\circ}$, Thomas H. Prettyman ${ }^{\mathrm{d}}$, \\ Christopher T. Russell ${ }^{\mathrm{f}}$, Carol A. Raymond ${ }^{\mathrm{p}}$, the Dawn Science Team
}

a School of Earth E' Space Exploration, Arizona State University, Tempe, AZ 85287-1404, USA

bohns Hopkins University Applied Physics Laboratory, Laurel, MD 20723, USA

${ }^{c}$ NASA Johnson Space Center, Houston, TX 77058, USA

d Planetary Science Institute, Tucson, AZ 85719, USA

e LPI, Houston, TX 77058, USA

${ }^{\mathrm{f}} U C L A$, Los Angeles, CA 90095, USA

g NASA Goddard Spaceflight Center, Greenbelt, MD 20771, USA

${ }^{\mathrm{h}}$ Bear Fight Center, Winthrope, WA 98862, USA

${ }^{i}$ DLR, Berlin, Germany

${ }^{\mathrm{j}}$ Brown University, Providence, RI 02912, USA

${ }^{\mathrm{k}}$ Max Planck Inst., Katlenburg-Lindau, Germany

${ }^{1}$ NASA Lunar Science Institute, Boulder, CO 80302, USA

${ }^{\mathrm{m}}$ Freie Universität, Berlin, Germany

${ }^{\mathrm{n}}$ Institut für Planetologie, Westfälische Wilhelms-Universität, Münster, Germany

${ }^{\circ}$ National Institute of Astrophysics, Rome, Italy

${ }^{\mathrm{p}}$ NASA JPL, California Institute of Technology, Pasadena, CA 91109, USA

\section{A R T I C L E I N F O}

\section{Article history:}

Received 14 March 2013

Revised 23 January 2014

Accepted 28 January 2014

Available online xxxx

\section{Keywords:}

Asteroid Vesta

Impact processes

Geological processes

\begin{abstract}
A B S T R A C T
We used Dawn spacecraft data to identify and delineate geological units and landforms in the Marcia quadrangle of Vesta as a means to assess the role of the large, relatively young impact craters Marcia ( $\sim 63 \mathrm{~km}$ diam.) and Calpurnia ( $\sim 53 \mathrm{~km}$ diam.) and their surrounding ejecta field on the local geology. We also investigated a local topographic high with a dark-rayed crater named Aricia Tholus, and the impact crater Octavia that is surrounded by a distinctive diffuse mantle. Crater counts and stratigraphic relations suggest that Marcia is the youngest large crater on Vesta, in which a putative impact melt on the crater floor ranges in age between $\sim 40$ and $60 \mathrm{Ma}$ (depending upon choice of chronology system), and Marcia's ejecta blanket ranges in age between $\sim 120$ and 390 Ma (depending upon choice of chronology system). We interpret the geologic units in and around Marcia crater to mark a major vestan time-stratigraphic event, and that the Marcia Formation is one of the geologically youngest formations on Vesta. Marcia crater reveals pristine bright and dark material in its walls and smooth and pitted terrains on its floor. The smooth unit we interpret as evidence of flow of impact melts and (for the pitted terrain) release of volatiles during or after the impact process. The distinctive dark ejecta surrounding craters Marcia and Calpurnia is enriched in $\mathrm{OH}$ - or $\mathrm{H}$-bearing phases and has a variable morphology, suggestive of a complex mixture of impact ejecta and impact melts including dark materials possibly derived from carbonaceous chondrite-rich material. Aricia Tholus, which was originally interpreted as a putative vestan volcanic edifice based on lower resolution observations, appears to be a fragment of an ancient impact basin rim topped by a dark-rayed impact crater. Octavia crater has a cratering model formation age of $\sim 280-990$ Ma based on counts of its ejecta field (depending upon choice of chronology system), and its ejecta field is the second oldest unit in this quadrangle. The relatively young craters and their
\end{abstract}

\footnotetext{
* Corresponding author. Fax: +1 4809658102.

E-mail address: david.williams@asu.edu (D.A. Williams).
} 
related ejecta materials in this quadrangle are in stark contrast to the surrounding heavily cratered units that are related to the billion years old or older Rheasilvia and Veneneia impact basins and Vesta's ancient crust preserved on Vestalia Terra.

(ㄷ) 2014 Elsevier Inc. All rights reserved.

\section{Introduction}

The asteroid Vesta displays a variety of impact crater-related features as revealed by NASA's Dawn spacecraft (Russell et al., 2012; Jaumann et al., 2012), including a region of overlapping large, relatively fresh craters with low albedo ejecta fields adjacent to the Vestalia Terra highlands, as revealed by 1:500,000 scale global geologic mapping (Yingst et al., in press). As part of a quadrangle mapping program devised to support the Dawn Science Team with geologic and stratigraphic analyses of Vesta's surface, we produced a 1:250,000 scale geologic map of the Av-8 Marcia quadrangle. In this paper we discuss insights into the geologic features and stratigraphic relations of the Marcia quadrangle using our new map, which was derived from the higher spatial resolution Low Altitude Mapping Orbit (LAMO) basemap than was used for the global map.

\section{Regional setting}

The Av- 8 Marcia quadrangle straddles the $180^{\circ}$ longitude in the equatorial region of Vesta, covering $144-216^{\circ}$ E longitude and $\pm 21^{\circ}$ latitude. Global geologic mapping of Vesta (Yingst et al., in press) recognized that the Marcia quadrangle occurs at the confluence of several units: (1) the south polar and southern latitude, relatively lightly-cratered floors of the Rheasilvia and Veneneia impact basins (called the Rheasilvia Formation); (2) the equatorial, highlycratered ridge and trough terrain called the Divalia Fossae Formation; (3) the equatorial, highly-cratered topographic highland called Vestalia Terra; and (4) the north polar and northern latitude, heavily-cratered terrain containing subdued ridges and troughs called the Saturnalia Fossae Formation. Superposed at this convergence of units are a series of larger, fresh craters and their ejecta, as well as several small bright and dark-rayed craters. Thus, our goal with the detailed mapping of the Marcia quadrangle is to better understand the geologic processes that have formed and modified the craters and other features in this region of Vesta, including understanding of the stratigraphic relations between the different units.

\section{Methods}

Detailed discussion of the basemap and supplemental materials used to make the quadrangle maps of Vesta, as well as the techniques and tools used, is given in the introductory paper (Williams et al., 2014). Briefly, we conducted iterative mapping of the Av-8 Marcia quadrangle using successively higher spatial resolution Framing Camera image mosaics obtained during the Survey ( $\sim 260 \mathrm{~m} /$ pixel), High Altitude Mapping Orbit (HAMO, $\sim 70 \mathrm{~m} /$ pixel), and LAMO ( $\sim 25 \mathrm{~m} /$ pixel, Fig. 1$)$ phases of the Dawn mission. Each mosaic was spatially co-registered to a digital terrain model (DTM, Fig. 2) developed during the prior phase (e.g., Survey mosaic registered to Hubble Space Telescope DTM, LAMO mosaic registered to HAMO DTM: see Preusker et al., 2012). Supplemental materials provided by the Dawn Science Team to aid in the mapping and interpretations included photometrically normalized

\footnotetext{
1 Clementine-type color ratio image: Red: 750/430 nanometers (nm); Green: 750/
} $920 \mathrm{~nm}$; Blue: 430/750 nm.
HAMO mosaics, false color ratio image mosaics using Clementinetype $^{1}$ ratios (Fig. 3; see also Reddy et al., 2012a,b), and topographic, slope, and contour maps derived from the various DTMs using ArcGIS $^{\text {TM }} 10$ software. Note that all Dawn data, including the maps and figures herein, are presented in the Dawn Claudia coordinate system (Russell et al., 2012; Roatsch et al., 2012), consistent with the Survey-based geologic map published in Jaumann et al. (2012) and all other published results by the Dawn Team. At the time of this writing, the Dawn data in the NASA Planetary Data System (PDS) has its prime meridian offset by $-150^{\circ}$ longitude, i.e., Claudia system longitude $=($ PDS 2013 longitude $)-150^{\circ}$.

\section{Results}

Geologic mapping of the Av-8 Marcia quadrangle has identified 15 units in this region (Figs. 4a and 4b and 5). In the following sections we discuss each of these map units, from oldest to youngest, based on correlation of stratigraphic relations (Fig. 6). Where possible, we have applied assessments of crater densities to obtain cratering model ages of crater units (Table 1 ) using both asteroid flux-based (Marchi et al., 2012a,b, 2013; O’Brien et al., submitted for publication) and lunar-derived chronologies (Schmedemann et al., submitted for publication). Using crater statistics on Vesta is particularly challenging because of the abundance of highly sloped surfaces (Jaumann et al., 2012) and the large degree of degradation and modification of craters (see Krohn et al., 2014), such that homogeneous units are sometimes difficult to recognize.

\subsection{Description of map units}

\subsubsection{Cratered highlands unit (ch, RGB color: 137-112-68)}

This unit is found in the northern and eastern portions of Marcia quadrangle, and consists of a heavily cratered terrain that is generally topographically lower than surrounding units because of many subcircular depressions containing ruined craters. It contains the highest crater density observed on Vesta (Marchi et al., 2012a,b). The unit displays intermediate albedo in FC monochrome images, blue-purple in FC color ratio images. Type area: lat $17^{\circ} \mathrm{N}$, long $154^{\circ} \mathrm{E}$. Interpretation: Vestan crustal material, heavily disrupted by impact and tectonic processes. This unit likely represents the

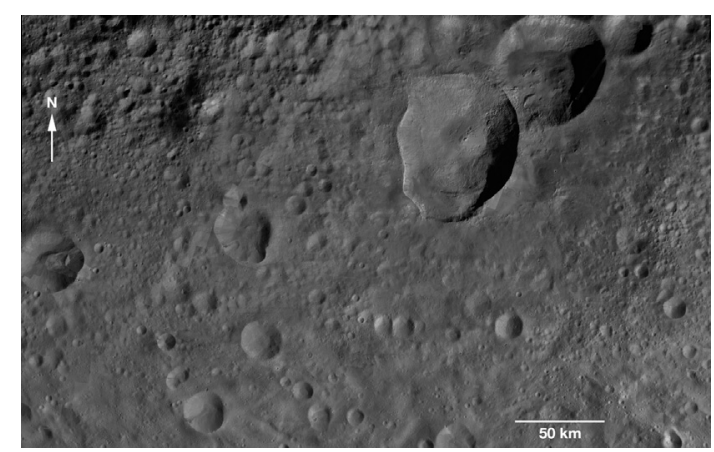

Fig. 1. NASA Dawn Framing Camera (FC) Low Altitude Mapping Orbit (LAMO) monochrome mosaic of Av-8 Marcia quadrangle. Spatial resolution is $25 \mathrm{~m} /$ pixel. Mosaic is Mercator projection, centered on longitude $180^{\circ}$ (Claudia coordinate system: Russell et al., 2012; Roatsch et al., 2012). 


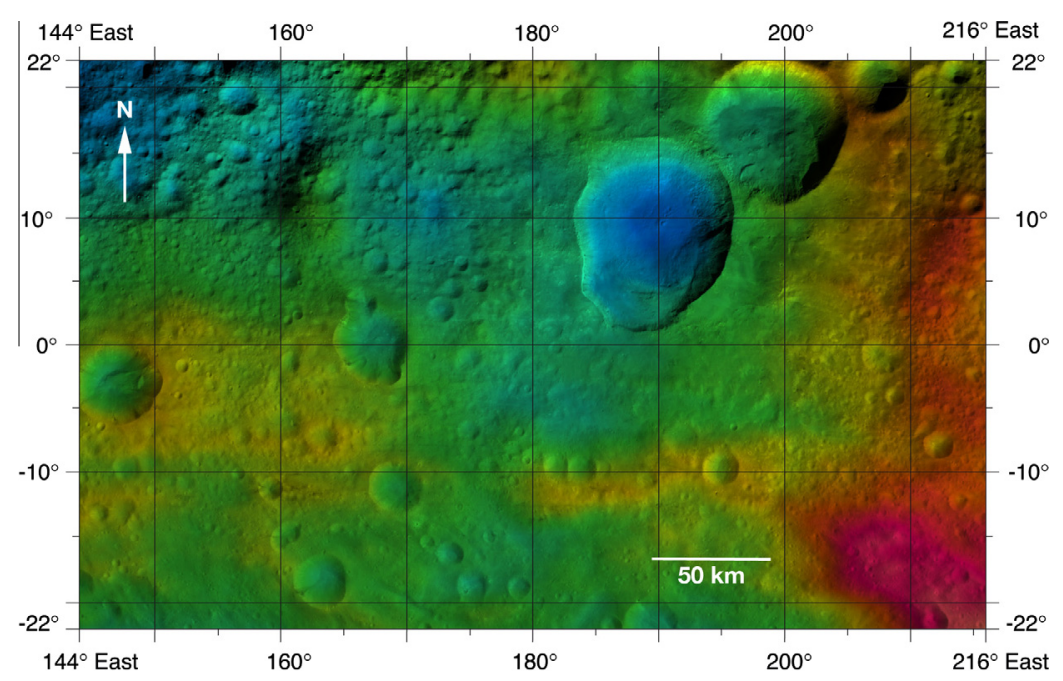

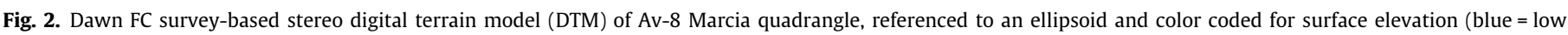

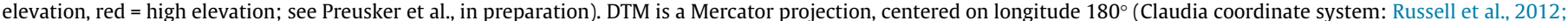
Roatsch et al., 2012).

oldest surface on Vesta. The portion of this unit that comprises Vestalia Terra is superposed by fresher ejecta from Cornelia crater, and also is superposed by the Rheasilvia Formation.

\subsubsection{Divalia Fossae Formation (Df, RGB color: 190-255-232)}

This unit is found in west-central parts of the Marcia quadrangle, in which the terrain is dominated by a heavily cratered surface and a portion of a prominent, unnamed ridge and flat-floored trough trending parallel to the equator and extending $\sim 76 \mathrm{~km}$ into this quadrangle. Numerous craters superpose the trough. This unit was named the Divalia Fossae Formation in the global map (Yingst et al., in press). This unit does not have a unique color in FC monochrome and color ratio images, but it displays an intermediate crater density between the cratered highlands unit and the Rheasilvia Formation. Type area: lat $0^{\circ} \mathrm{N}$, long $156^{\circ} \mathrm{E}$. Interpretation: Vestan crustal material, heavily disrupted by impact and tectonic processes. Tectonic analysis (Buczkowski et al., 2012) is consistent with interpretation that equatorial troughs, such as the Divalia Fossae formed by tectonic response to formation of the Rheasilvia impact basin.

\subsubsection{Rheasilvia Formation, Smooth member (Rs, RGB color: 190-210-} 255)

This unit is found in southern parts of Marcia quadrangle, in which the terrain is dominated by a hummocky surface covered with high albedo lobate features and small craters. Many of the larger craters have subdued rims with floors containing additional lobate features. The location of this unit marks the floor and part of the rim of the ancient Veneneia impact basin that pre-dates the Rheasilvia basin. The topography of this unit shows that it is generally lower than that of the Divalia Fossae Formation, although the southern part of Vestalia Terra may be partly covered by this unit. Type area: lat $17^{\circ} \mathrm{S}$, long $165^{\circ} \mathrm{E}$. Interpretation: Vestan crust that is mantled by Rheasilvia and possibly Veneneia impact ejecta. The lobate features on the crater floors within this unit may be mass wasting deposits, or Rheasilvia ejecta.

\subsubsection{Tholus unit ( $t, R G B$ color: $230-0-0$ )}

This unit, defined by a feature named Aricia Tholus, is a domical to elongate region of elevated topography superposed by a darkrayed impact crater. Analysis of photometrically corrected images was required to separate the extent of dark ejecta on this feature

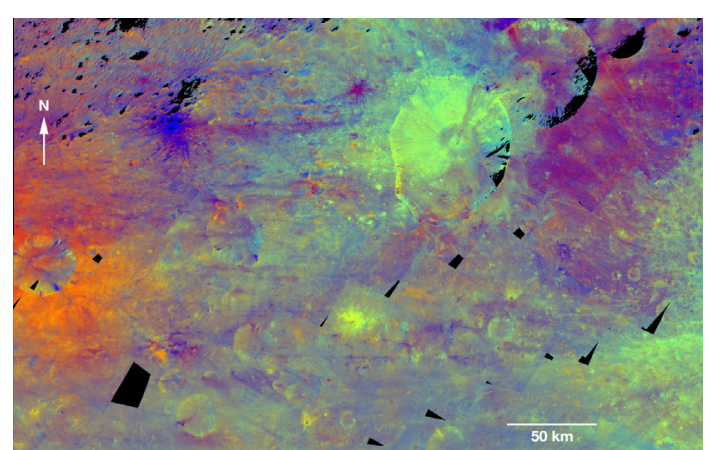

Fig. 3. FC HAMO-derived Clementine-type color ratio mosaic of Av-8 Marcia quadrangle. Spatial resolution is $70 \mathrm{~m} /$ pixel. Colors correspond to Red: $750 / 430 \mathrm{~nm}$, Green: $750 / 920 \mathrm{~nm}$, and Blue $430 / 750 \mathrm{~nm}$. Mosaic is Mercator projection, centered on longitude $180^{\circ}$ (Claudia coordinate system: Russell et al., 2012; Roatsch et al., 2012).

from shadowed terrain. Analysis of the DTM indicates that the tholus is located on the western margin of an ancient depression. Type area: lat $12^{\circ} \mathrm{N}$, long $162^{\circ} \mathrm{E}$. Interpretation: A topographic dome, most likely impact-sculpted vestan crust, that is either the remnant of an ancient impact basin rim (in which the dark-rayed crater represents material from an exogenic dark impactor), or alternatively part of a volcanic dike in which the impactor has exposed dark material.

\subsubsection{Undivided crater ejecta unit (uc, 230-230-0)}

This unit is characterized by a hummocky surface with a variable extent in all directions around the craters Marcia, Calpurnia, and Minucia. This unit has a low albedo (dark purple color in FC color ratio images) on the east side of Marcia and Calpurnia, but a higher albedo on the western side. This unit contains the lowest crater abundance in the quadrangle, and is superposed by less areally extensive but more distinctive bright and dark lobate units and bright and dark rayed crater units. Type area: lat $2^{\circ} \mathrm{S}$, long $193^{\circ} \mathrm{E}$. Interpretation: Ejecta field formed from Calpurnia and Marcia impact events, with variable albedo and morphology. Brighter areas may be distinct impact ejecta outcrops, whereas darker areas may be some combination of impact ejecta and impact melt deposits. Small bright spots in color ratio images could be Marcia secondary craters. 


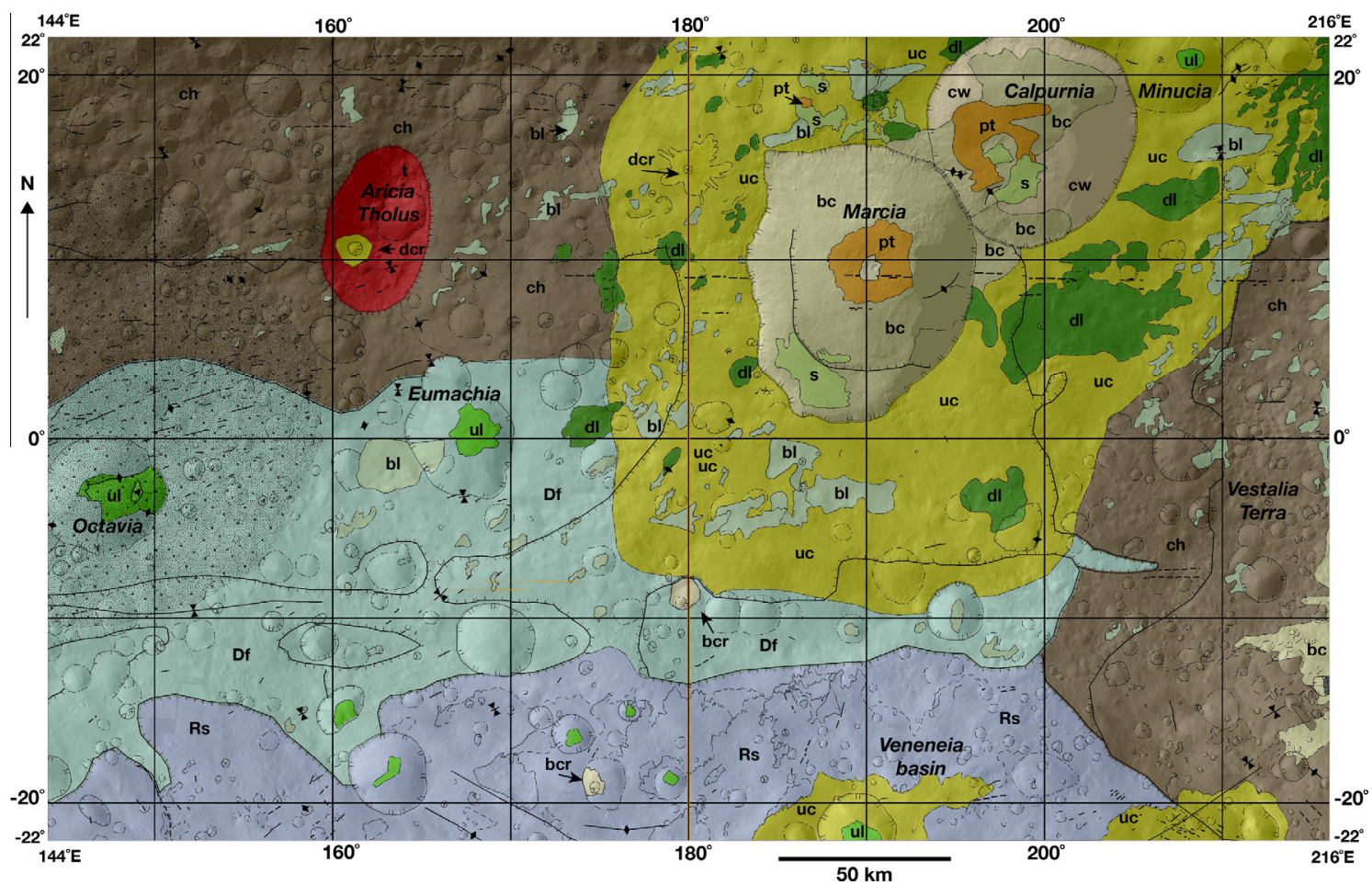

Fig. 4a. LAMO-based geologic map of Av-8 Marcia quadrangle. Map units and colors consistent with HAMO-based global geologic map of Vesta (Yingst et al., in press).

\section{Map Legend}

\begin{tabular}{|c|c|}
\hline Locatio & Features \\
\hline & vents \\
\hline LinearF & atures \\
\hline - & sinuous channel or groove \\
\hline & crest of buried crater \\
\hline П & crest of crater rim \\
\hline & depression margin \\
\hline & dome margin \\
\hline & graben trace, approx. \\
\hline & groove \\
\hline & lineament \\
\hline & ridge crest (type 1), certain \\
\hline & $\begin{array}{l}\text { scarp base } \\
\text { scarp crest }\end{array}$ \\
\hline & trough \\
\hline GeoCon & acts \\
\hline & boundary \\
\hline- & approximate \\
\hline (n...... & concealed \\
\hline$\||||||| \mid$ & gradational \\
\hline--- & inferred \\
\hline
\end{tabular}

cw Crater wall material ejecta)

\begin{tabular}{|c|l|}
\hline ul & $\begin{array}{l}\text { Undivided lobate } \\
\text { material }\end{array}$ \\
\hline bcr & $\begin{array}{l}\text { Bright crater ray } \\
\text { material }\end{array}$
\end{tabular}

dcr Dark crater ray material

bl Bright lobate material

dl Dark lobate material

pt Pitted terrain

bc Bright crater material sm

Smooth material

uc

\section{Undivided crater}

ejecta material

$\mathrm{t}$ Tholus material

\begin{tabular}{|l|l|}
\hline Rs & $\begin{array}{l}\text { Rheasilvia Formation: } \\
\text { Smooth terrain }\end{array}$ \\
\hline Df & Divalia Fossa Formation \\
\hline ch & Cratered highlands material \\
\hline
\end{tabular}

Fig. 4b. Map legend for the Av-8 Marcia quadrangle geologic map shown in Fig. 4a.

\subsubsection{Smooth unit (s, RGB color: 209-255-115)}

This unit is composed of an overall smoother and relatively lightly cratered surface at highest resolution (tens of meters scale) compared to all other units (e.g., bl, dl, pt), with a variable albedo. This unit is found in apparent topographic lows on the $\mathrm{N}$ rim of Marcia, and on a topographic 'bench' on the floor of Marcia. The unit boundaries range from crisp to ill-defined. The unit is separated from the rest of the crater floor by a scarp, and it contains some lobes; the unit on Calpurnia's floor has a more hummocky surface. Type area: lat $3^{\circ} \mathrm{N}$, long $187^{\circ} \mathrm{E}$. Interpretation: This unit, where it occurs within Marcia and Calpurnia, is likely to be impact melt deposits that moved downhill by gravity-driven flow. The unit occurrences on the north rim of Marcia could also be impact melts, or alternatively accumulations of fine-grained materials deposited by mass movement.

\subsubsection{Crater wall unit (cw, RGB color: 255-235-175)}

This unit, which occurs mostly in Calpurnia crater, is characterized by a relatively lower albedo surface than Bright crater material, containing pits, alcoves, linear outcrops, and small debris flows that deposit boulders downslope at the tens of meters scale. Type area: lat $19^{\circ} \mathrm{N}$, long $203^{\circ} \mathrm{E}$. Interpretation: Crust excavated by 

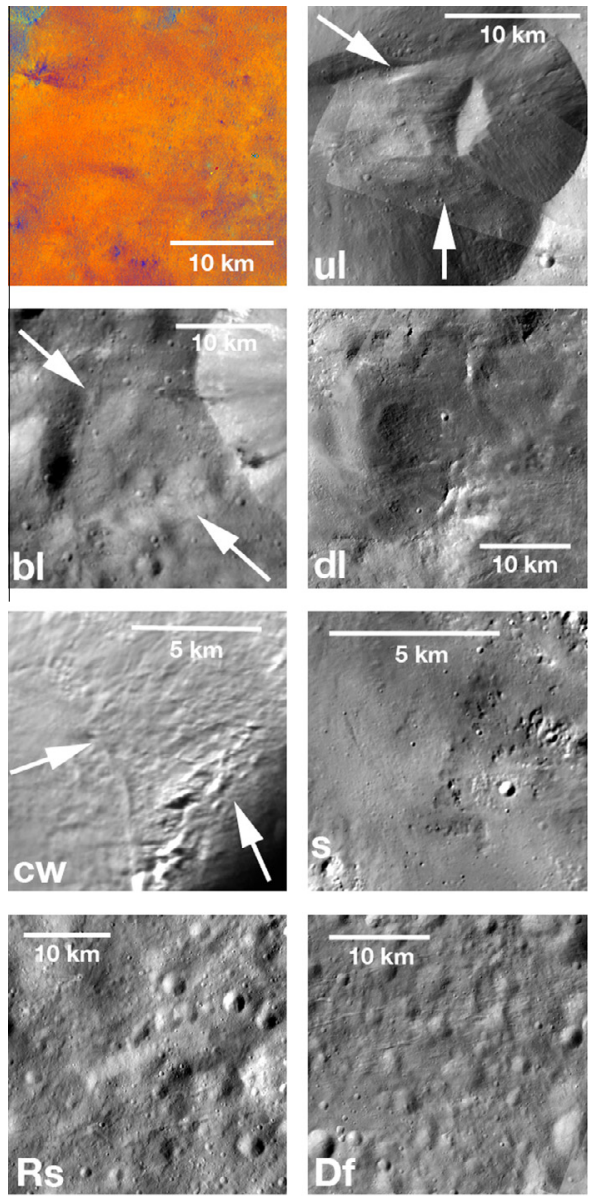
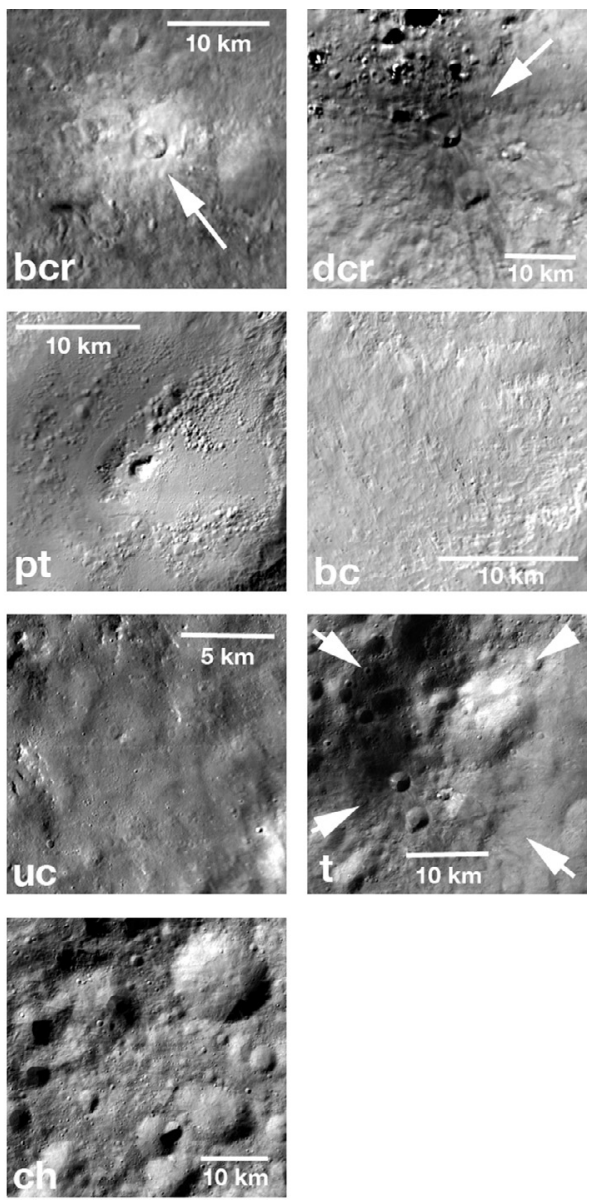

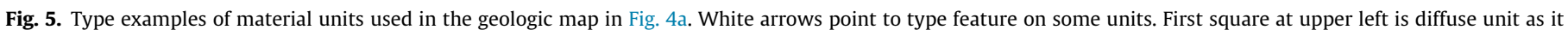
appears in false color ratio image.

Calpurnia crater that is not covered by younger Marcia ejecta. Likely contains some component of impact melts and mass wasting deposits.

\subsubsection{Bright crater unit (bc, RGB color: 230-230-150)}

This unit, which occurs on the walls and floors of Marcia and Calpurnia, is characterized by a relatively high albedo surface containing pits, alcoves, linear chains of outcrops, and small debris accumulations that deposit boulders downslope at the tens of meters scale. VIR data shows an enhanced signature of pyroxene, indicative of less space-weathered material. Type area: lat $13^{\circ} \mathrm{N}$, long $188^{\circ} \mathrm{E}$. Interpretation: Relatively fresh ejecta from the Marcia impact event, covering the inner walls of Marcia and Calpurnia craters. Could contain some component of impact melts and mass wasting deposits.

\subsubsection{Pitted terrain unit ( $p t, R G B$ color: $255-170-0$ )}

This unit is composed of a variably pitted surface with pits occurring over a range of sizes from hundreds of meters down to the limit of LAMO resolution, and as single pits or clusters of a few large pits surrounded by irregular clusters of many small pits. There is no pattern recognizable in the pit distributions indicative of impact crater secondaries or pit chains associated with graben, and the pits are typically rimless. The unit of Pitted Terrain on the floor of Marcia surrounds a central topographic high, separated by a shallow scarp. Type area: lat $9^{\circ} \mathrm{N}$, long $191^{\circ} \mathrm{E}$. Interpretation: Impact ejecta or impact melt sheets modified by the release of volatiles (Denevi et al., 2012), likely containing superposed crater wall material in distal margins. The volatiles could have been derived target rock disrupted by impacts. Furthermore, the relatively young age inferred for this unit discounts a volcanic origin.

\subsubsection{Dark lobate unit (dl, RGB color: $56-168-0$ )}

This unit is composed of lobate masses of relatively low albedo in monochrome FC images (dark purple color in FC color ratio images), found mostly within or near the Marcia crater ejecta field. The upper surface of this unit is typically hummocky and may have a rough texture, with a lower crater abundance than Bright lobate material. Type area: lat $6^{\circ} \mathrm{N}$, long $200^{\circ} \mathrm{E}$. Interpretation: Crust covered by a thick mantle of low albedo crater ejecta, possibly also including a component of low albedo impact melts.

\subsubsection{Bright lobate unit (bl, RGB color: 211-255-190)}

This unit is composed of lobate masses of relatively intermediate to high albedo in monochrome FC images, found mostly within the Marcia ejecta field, although a large deposit is located on the rim of Eumachia crater, trending downslope both into and away from the crater rim. The upper surface of this unit is typically hummocky and covered with small craters, although some outcrops are smooth and relatively featureless. Type area: lat $1^{\circ} \mathrm{S}$, long $163^{\circ} \mathrm{E}$. Interpretation: Crust covered by a thick mantle of high albedo crater ejecta, possibly also including a component of high albedo impact melts. Some accumulations in topographic lows or on slopes could be regolith transported by mass movement processes. 


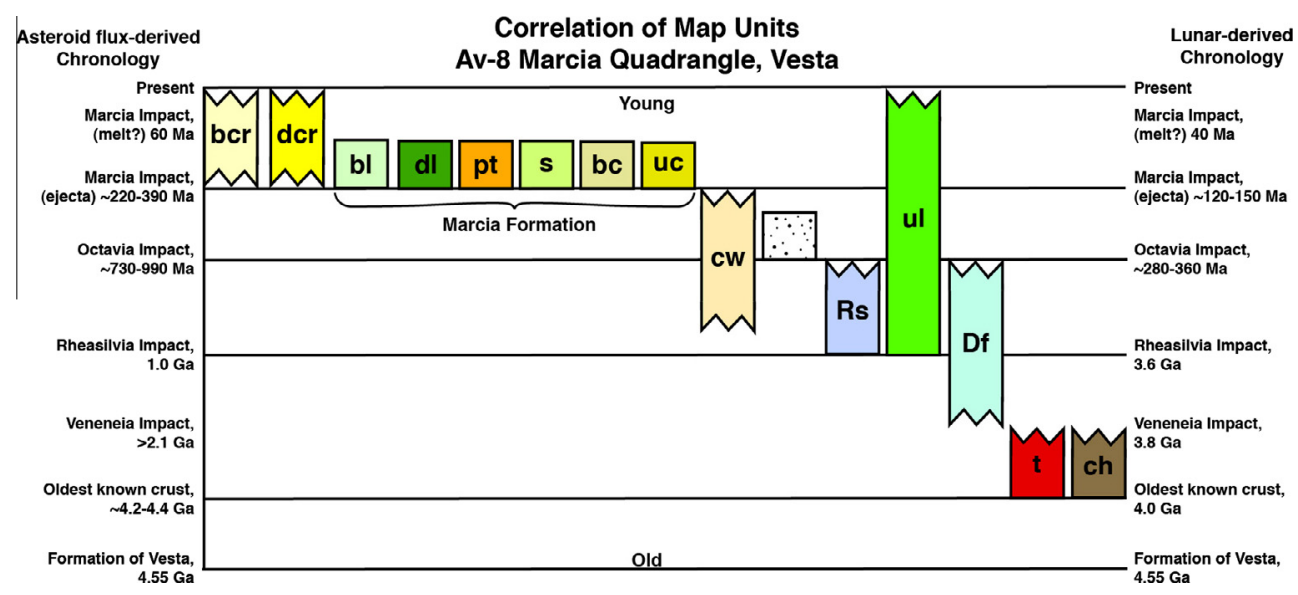

Fig. 6. Correlation of Map Units (COMU) for the Av-8 Marcia quadrangle geologic map in Fig. 4a.

Table 1

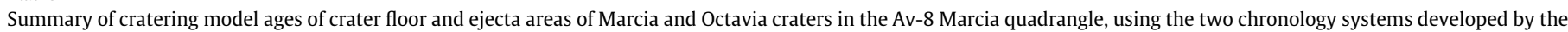
Dawn Science Team. Refer to Fig. 14a for the count areas.

\begin{tabular}{|c|c|c|c|c|c|c|c|}
\hline \multirow[t]{2}{*}{ Unit name } & \multicolumn{3}{|c|}{ Lunar-derived chronology } & \multicolumn{3}{|c|}{ Asteroid flux-derived chronology } & \multirow[t]{2}{*}{ Additional data } \\
\hline & $\mathrm{N}(1)\left(\mathrm{km}^{-2}\right)$ & $\begin{array}{l}\text { Cratering } \\
\text { model age } \\
(\mathrm{Ma})\end{array}$ & $\begin{array}{l}\text { Fit diameter } \\
\text { range }(\mathrm{km})\end{array}$ & $\mathrm{N}(1)\left(\mathrm{km}^{-2}\right)$ & $\begin{array}{l}\text { Cratering } \\
\text { model age } \\
(\mathrm{Ma})\end{array}$ & $\begin{array}{l}\text { Fit diameter } \\
\text { range }(\mathrm{km})\end{array}$ & \\
\hline Marcia ejecta blanket, Area 5a & $2.51 \times 10^{-3}$ & $123 \pm 9.3$ & $0.17-0.9$ (170 craters) & $7.18 \times 10^{-3}$ & $358 \pm 22$ & $0.14-1$ (244 craters) & Area: $2.83 \times 10^{2} \mathrm{~km}, 282$ craters counted \\
\hline Marcia ejecta blanket, Area 5b & $2.82 \times 10^{-3}$ & $138 \pm 56$ & $0.45-0.8$ (6 craters $)$ & $4.47 \times 10^{-3}$ & $223 \pm 83$ & $0.4-0.8$ ( 7 craters $)$ & Area: $1.84 \times 10^{2} \mathrm{~km}, 93$ craters counted \\
\hline Marcia ejecta blanket, Area $5 c$ & $2.45 \times 10^{-3}$ & $120 \pm 12$ & $0.3-0.7$ (52 craters) & $5.89 \times 10^{-3}$ & $294 \pm 27$ & $0.25-0.6$ (69 craters) & Area: $5.15 \times 10^{2} \mathrm{~km}, 148$ craters counted \\
\hline Marcia ejecta blanket, Area $5 \mathrm{~d}$ & $3.03 \times 10^{-3}$ & $149 \pm 16$ & $0.25-0.7$ (73 craters) & $7.90 \times 10^{-3}$ & $394 \pm 41$ & $0.25-1$ (77 craters) & Area: $4.27 \times 10^{2} \mathrm{~km}, 106$ craters counted \\
\hline Marcia crater floor, Area 5e & $8.47 \times 10^{-4}$ & $42 \pm 12$ & $0.25-0.7$ (12 craters) & $1.22 \times 10^{-3}$ & 60 & & Area: $1.85 \times 10^{2} \mathrm{~km}, 277$ craters counted \\
\hline Octavia ejecta blanket, Area 2a & $7.36 \times 10^{-3}$ & $362 \pm 26$ & $0.35-0.8$ (127 craters $)$ & $1.82 \times 10^{-2}$ & $902 \pm 64$ & $0.35-1.2$ (144 craters) & Area: $7.32 \times 10^{2} \mathrm{~km}, 272$ craters counted \\
\hline Octavia ejecta blanket, Area 2b & $5.67 \times 10^{-3}$ & $278 \pm 23$ & $0.25-1$ (125 craters) & $1.47 \times 10^{-2}$ & $730 \pm 60$ & $0.25-0.6$ (115 craters) & Area: $3.11 \times 10^{2} \mathrm{~km}, 200$ craters counted \\
\hline Octavia ejecta blanket, Area $2 \mathrm{c}$ & $7.33 \times 10^{-3}$ & $360 \pm 22$ & $0.25-0.8$ (231 craters) & $2.00 \times 10^{-2}$ & $991 \pm 68$ & $0.3-0.8$ (166 craters) & Area: $5.29 \times 10^{2} \mathrm{~km}, 289$ craters counted \\
\hline
\end{tabular}

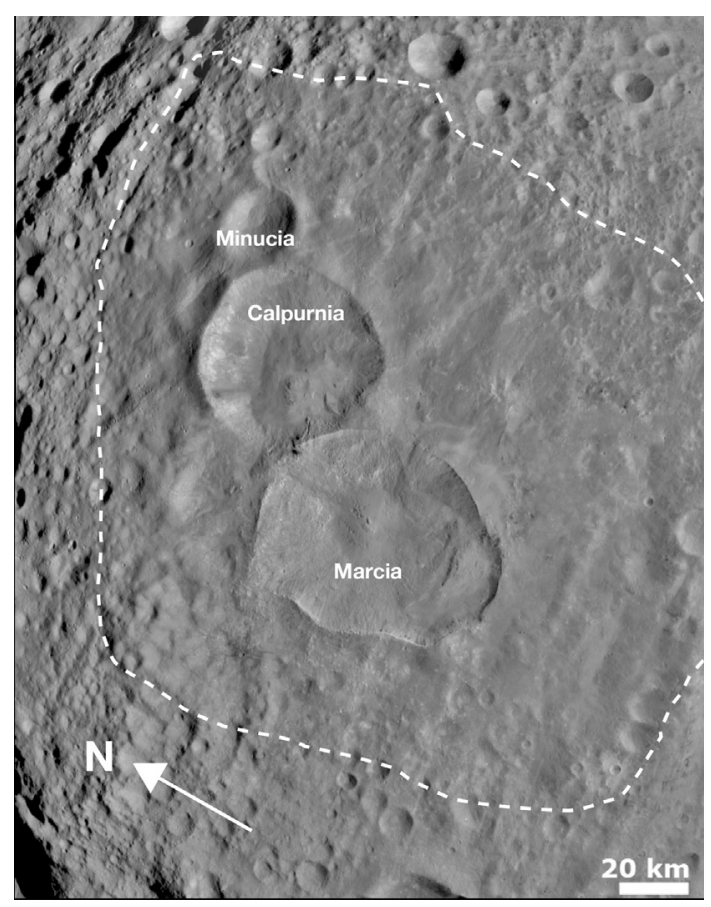

Fig. 7. Dawn FC survey orbit image of the 'snowman' impact craters. From oldest to youngest are impact craters Minucia ( $21.5 \mathrm{~km}$ diameter), Calpurnia ( $\sim 50 \mathrm{~km}$ diameter), Marcia ( $\sim 58 \mathrm{~km}$ diameter). Dashed white line marks the continuous ejecta field as first observed during Dawn's Survey orbit. Image \#F2365891958 (spatial resolution of $260 \mathrm{~m} /$ pixel).

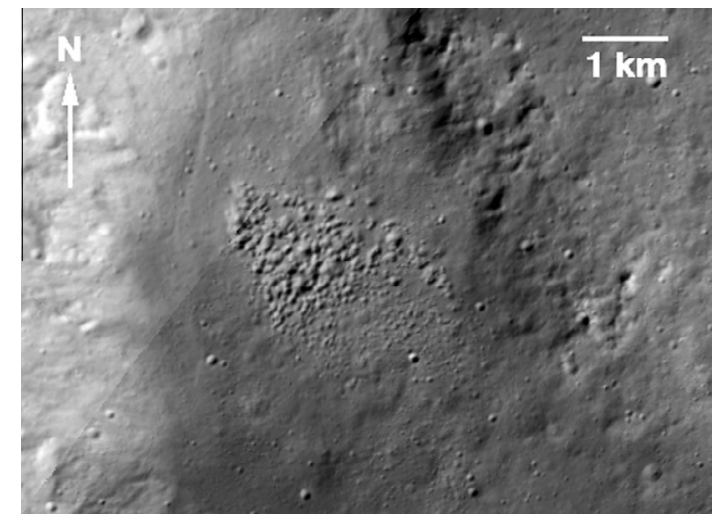

Fig. 8. A small section of pitted terrain within smooth terrain on the NW rim of crater Marcia. Study of this pitted terrain (Denevi et al., 2012) noted its resemblance to similar material on Mars (Abramov, 2006; Boyce et al., 2012; Tornabene et al., 2012), suggesting that it could be related to release of volatiles, in this case derived either from the Marcia impactor or the vestan crust.

\subsubsection{Dark crater ray unit (dcr, RGB color: 255-255-0)}

This unit occurs around impact craters, forming radial haloes, streaks or patches over underlying topography and extending to or beyond one crater diameter. The distribution of this unit around craters is often asymmetrical. This unit displays a low albedo in monochrome FC images and a dark purple color in FC color ratio images. This unit generally shows a decreasing opacity with increasing distance from source. Type area: lat $10^{\circ} \mathrm{N}$, long $161^{\circ} \mathrm{E}$. Interpretation: Low albedo impact ejecta dispersed from a possibly 


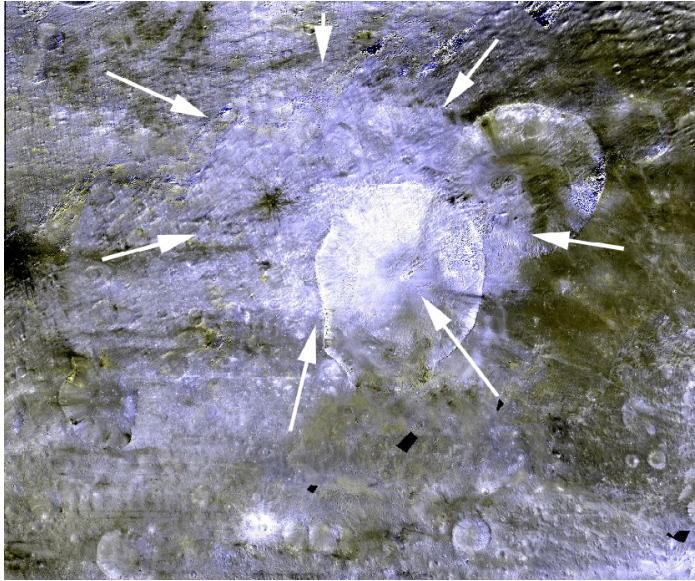

Fig. 9. Dawn FC image mosaic showing the spectral signature of a potential earlier impact (outlined by white arrows) centered near the northwestern rim of Marcia. This sharp eccentric boundary is without counterpart in the DTM, which would be unexpected for an ejecta sheet from Marcia, and in fact does not coincide with that respective unit. The different spectral properties can be explained as a result of a major earlier impact that replaced the surface material with a mixture of deeper layers. Then the later Marcia impact and its ejecta erased most the topographic signature of the earlier event. In the northwestern part of Marcia, near the center of the old impact, the change of the composition is more prominent because of the more distinct combination of the excavated material. Red and Green channels $440 \mathrm{~nm}^{3} /(650 \mathrm{~nm} * 750 \mathrm{~nm} * 830 \mathrm{~nm})$, Blue channel: $960 \mathrm{~nm} / 830 \mathrm{~nm}$. (For interpretation of the references to colour in this figure legend, the reader is referred to the web version of this article.)

carbonaceous impactor; alternatively, some deposits could consist of a layer of low albedo materials excavated from underneath a covering of bright ejecta, similar to lunar dark halo craters (e.g., Hawke and Bell, 1981).

\subsubsection{Bright crater ray unit (bcr, RGB color: 255-255-190)}

This unit occurs around impact craters, forming radial haloes, streaks or patches over underlying topography and extending to or beyond one crater diameter. Deposits have a high albedo in monochrome FC images, a bright white to yellow color in FC color ratio images. This unit generally shows a decreasing opacity with increasing distance from source. Type area: lat $8^{\circ} \mathrm{S}$, long $180^{\circ}$. Interpretation: High albedo impact ejecta consisting of materials excavated from Vesta; analogous to lunar crater rays.

\subsubsection{Undivided lobate unit (ul, RGB color: 85-255-0)}

This unit forms in topographic lows on crater floors. It contains lobate margins and hummocky to smooth surfaces. The albedo of this unit is similar to surrounding units. Type area: lat $3^{\circ} \mathrm{S}$, long $148^{\circ} \mathrm{E}$. Interpretation: Debris falls, slumps or slides resulting from a number of possible mass wasting processes, including gravitational settling, "seismic" shaking associated with impact crater formation, or slope failure.

\subsubsection{Dark diffuse unit (spotted pattern overlying other units)}

This unit occurs around Octavia crater. This unit forms a radial halo where the underlying topography is still apparent, extending beyond one crater diameter. The halo is asymmetric with a wider dispersal to the northwest of the crater, spanning $\sim 190 \mathrm{~km}$ on its longest axis (Le Corre et al., 2013). The deposit displays a low albedo in monochrome FC images, but displays a distinctive bright orange color in FC false color ratio images. The composition of this colored material remains unclear, but comparison of FC color and VIR spectra with laboratory spectra of HED meteorites is most consistent with a mixture of impact melt and howardite (Le Corre et al., 2013). This unit generally displays decreasing opacity with increasing distance from source. Type area: lat $6^{\circ} \mathrm{S}$, long $152^{\circ} \mathrm{E}$. Interpretation: Diffuse deposit of impact ejecta and/or impact melt that thinly mantles underlying topography, perhaps including excavated Veneneia ejecta (cf., Le Corre et al., 2013). Distinctive color in color ratio images suggests unique composition, different from that at Oppia crater (Le Corre et al., 2013). Asymmetry of the halo suggests an impact from the southeast.
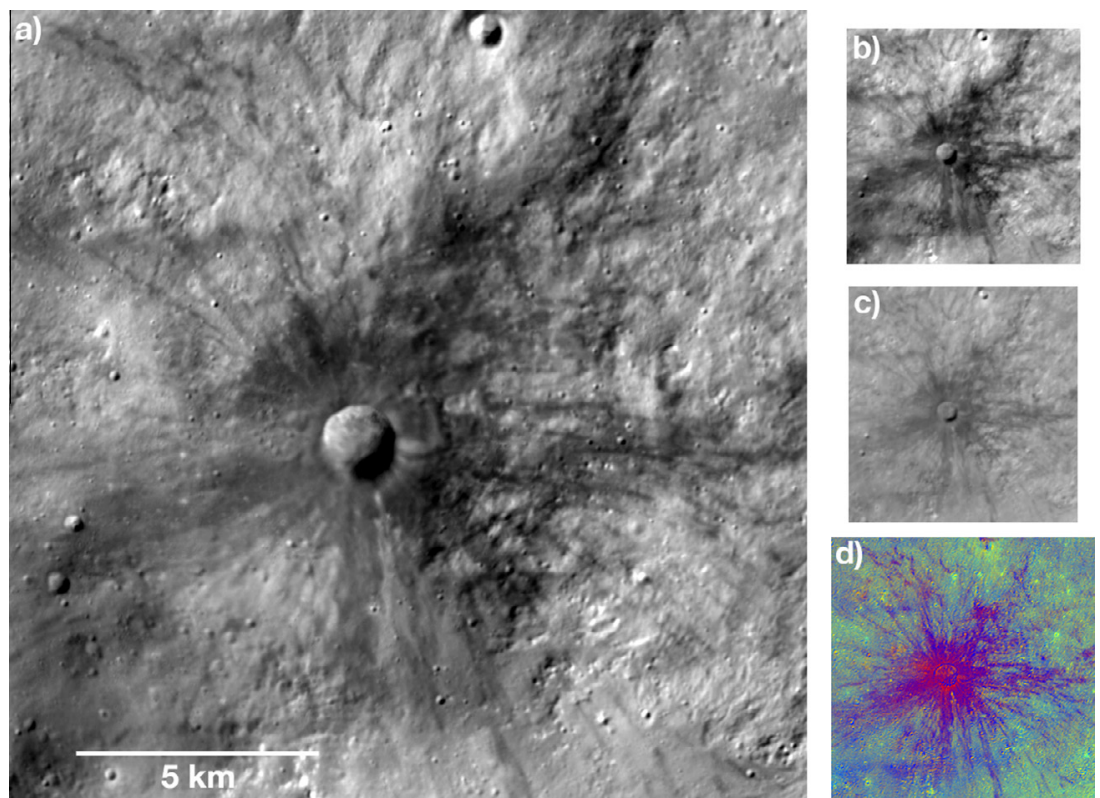

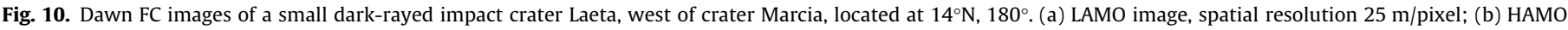

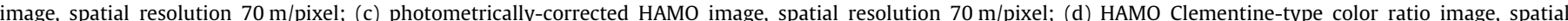

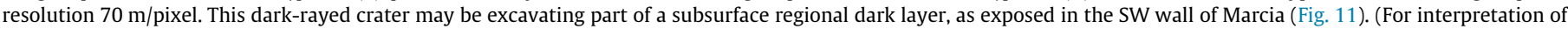
the references to colour in this figure legend, the reader is referred to the web version of this article.) 


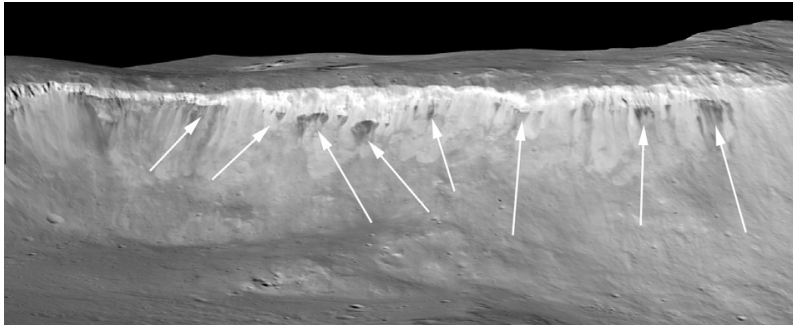

Fig. 11. Perspective view of part of the western rim of Marcia crater, looking west, showing outcrops of dark material (white arrows) weathering out underneath bright material, perhaps fresh Marcia ejecta (after McCord et al., 2012). Dawn FC LAMO mosaic overlain on HAMO DTM. Image processing by David O'Brien, Planetary Science Institute.

\subsection{Geologic synthesis}

\subsubsection{Craters Marcia, Calpurnia, and Minucia}

The most prominent features in the quadrangle are three impact craters named Marcia, Calpurnia, and Minucia and their surrounding ejecta fields, which were first recognized in Dawn FC Approach and Survey images (Fig. 7). The low albedo ejecta field east of Marcia corresponds to the low albedo feature unofficially named 'Olbers' in HST images (Thomas et al., 1997b). Marcia is $68 \mathrm{~km}$ long $(\mathrm{N}-\mathrm{S})$ by $58 \mathrm{~km}$ wide $(\mathrm{E}-\mathrm{W})$. Calpurnia just to the NE is $54 \mathrm{~km}$ long $(\mathrm{N}-\mathrm{S})$ by $52 \mathrm{~km}$ wide $(\mathrm{E}-\mathrm{W})$, and Minucia to the $\mathrm{NE}$ is $26 \mathrm{~km}$ long $(\mathrm{N}-\mathrm{S})$ by $23 \mathrm{~km}$ wide $(\mathrm{E}-\mathrm{W})$. The ejecta surrounding these craters dominate from the center to the northeast border of this quadrangle, and extend into the neighboring Av-4 Domitia quadrangle to the north (Roatsch et al., 2012; Ruesch et al., 2014; Scully et al., 2014).

We mapped the morphology and preservation state of these craters, from which we infer the stratigraphic sequence of formation: Minucia is the oldest, followed by Calpurnia, and lastly Marcia. This result is based on the following: (1) Minucia does not have a well-defined rim; it has a low depth-to-diameter ratio compared to other craters its size (Vincent et al., in press), and it has an apparent mass wasting deposit on its floor; (2) the presence of Marcia ejecta superposed on the floor and SW rim of Calpurnia; and (3) the relative sharp rim (well-defined topographic scarp) of Marcia compared to Calpurnia and Minucia, the relatively pristine nature of its inner wall and floor deposits, and the exposure of relatively fresh bright and dark material in Marcia's SW inner wall (McCord et al., 2012; Reddy et al., 2012b). VIR data show an enhanced spectral signature of pyroxene in the inner walls of Marcia crater compared to its surroundings, in which stronger spectral signatures correspond to relatively unweathered bright outcrops (McCord et al., 2012; Li et al., in preparation).

Craters Marcia and Calpurnia display pitted terrain and smooth terrain (Denevi et al., 2012), and it is possible that the Calpurnia pitted terrain could have come from Marcia ejecta. Using LAMO images, we were able to map these terrains as discrete geologic units. Pitted terrain, located on the floors of Marcia, Calpurnia (although smoother and much less pitted), and a small deposit off the north rim of Marcia (Fig. 8), are characterized by their pitted surfaces with pits occurring over a range of sizes from hundreds of meters down to the limit of LAMO resolution. Pits occur as individuals or as clusters of a few large pits surrounded by irregular clusters of many small pits. There is no pattern recognizable in the pit distributions consistent with impact crater secondaries or pit chains associated with graben formation, and they lack rims typical of an impact origin (Denevi et al., 2012). Pitted terrain on the floor of Marcia surrounds a central topographic high, which we interpret as an incipient central peak), separated by a shallow scarp, similar to a high lava mark produced by drainage of a fluid flow. The resemblance of this vestan pitted terrain to similar materials on Mars thought to be derived from volatile release processes

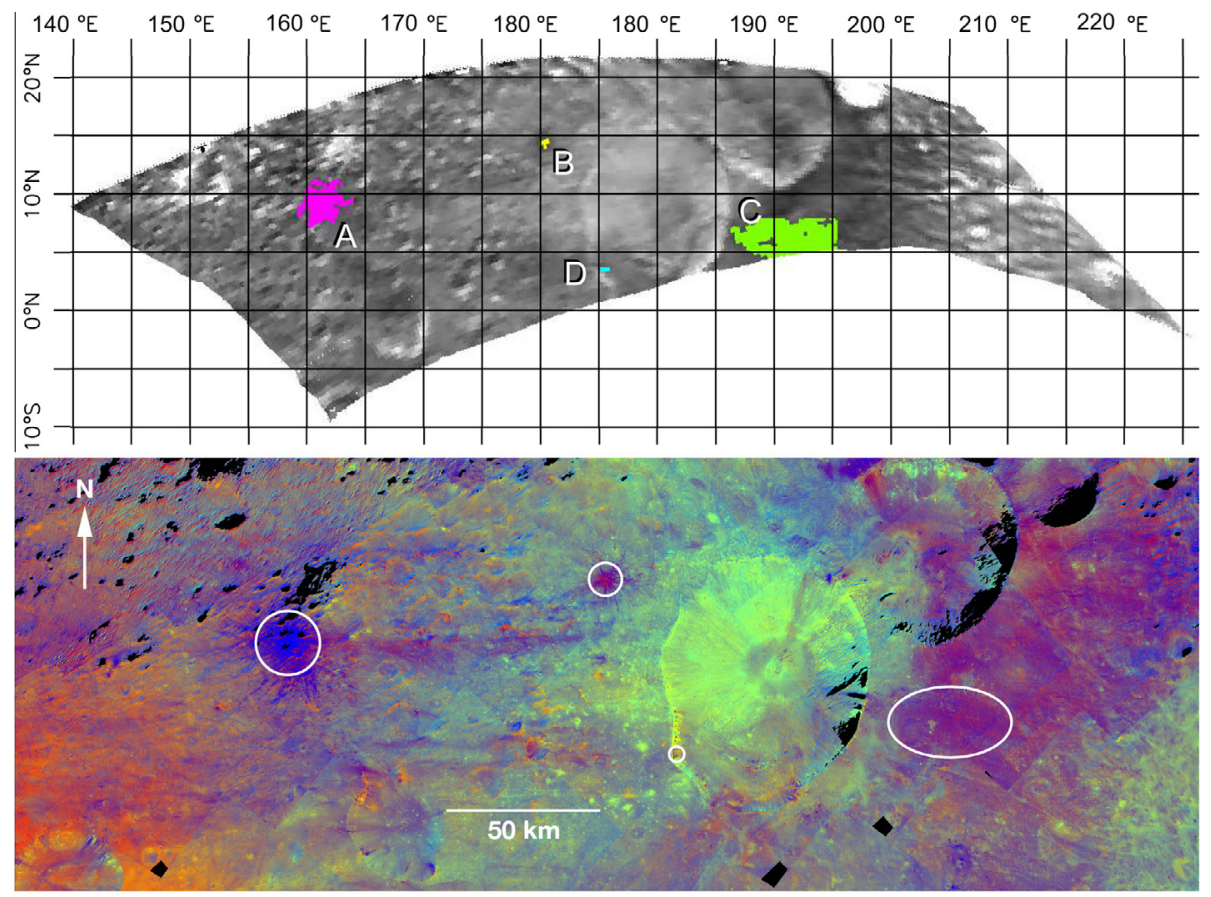

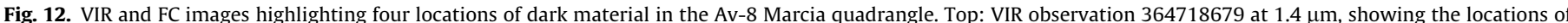

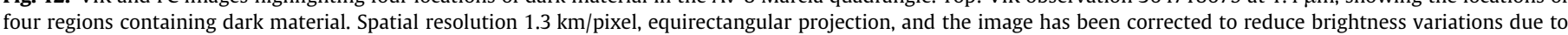

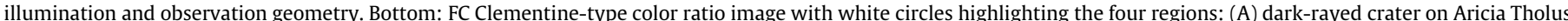

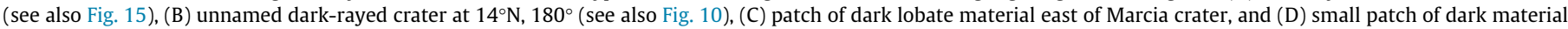
exposed below bright material in Marcia crater rim (see also Fig. 1 and McCord et al., 2012). 


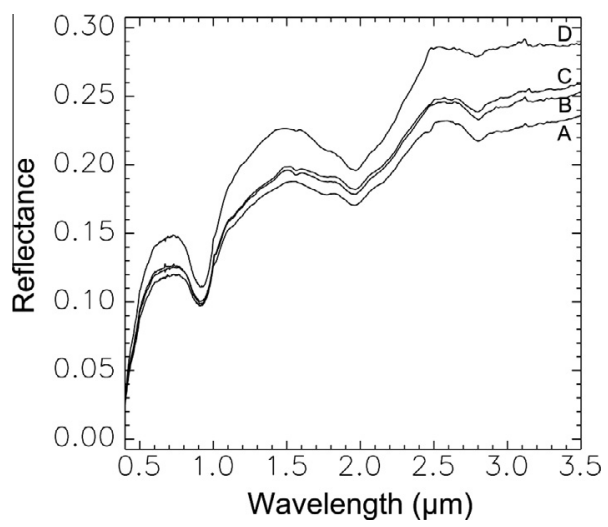

Fig. 13. VIR spectra of four dark material regions as indicated in Fig. 12. The spectra are averages over each region. The plot illustrates that the various dark materials are spectrally similar, except for the degree of purity because of contamination by ejecta. Region D (Marcia wall) has a relatively higher reflectance value than the others, mostly because the spatial resolution of this VIR observation is not enough to resolve the small dark patch at the surface.

(Abramov, 2006; Boyce et al., 2012; Tornabene et al., 2012) suggested to Denevi et al. (2012) that these terrains might be impact ejecta or impact melt sheets modified by the release of volatiles. The volatiles could have been derived from the ancient Veneneia impactor (Reddy et al., 2012b), or from carbonaceous chondriterich material on the upper surface of Vesta prior to the Marcia impact (De Sanctis et al., 2012b). There is no evidence from either the HED meteorites or from analyses of Vesta's surface to suggest a volcanic origin for the pitted terrain (e.g., volcanic vents, pyroclastic deposits, etc.).

Vesta's global distribution of OH from VIR data and $\mathrm{H}$ abundance from GRaND data is such that the strongest absorptions of hydration are associated with the very large region of dark material, between $70^{\circ}$ to $220^{\circ}$ and $30^{\circ} \mathrm{N}$ to $30^{\circ} \mathrm{S}$ (De Sanctis et al., 2012b; Prettyman et al., 2012). McCord et al. (2012) suggested that slow accumulation of dark material deposited from carbonaceous asteroids over time prior to the Rheasilvia impact might explain this dark region, whereas Reddy et al. (2012b) suggested that the dark material might have been deposited by the ancient Veneneia impact event. In this quadrangle, we observe dark material on the NE Calpurnia crater floor as well as the ejecta field east of Marcia, and that bright Marcia ejecta with its strong pyroxene, weak $\mathrm{OH}-$ absorption bands superposes the dark material. This observation suggests that either Calpurnia formed before the dark material was emplaced, or that the Calpurnia event redistributed or deposited additional dark material. However, the relatively well-defined rim of Calpurnia suggests that it was not formed by an ancient event such as the Veneneia impact (cf., Minucia, which is much older). The dark material is superposed by the younger Marcia crater, which is poor in OH-bearing phases (De Sanctis et al., 2012b; Prettyman et al., 2012) with respect to the surroundings. The signature of $\mathrm{OH}$ in the local target rock could have been obscured by large impact events that dispersed deeper and less $\mathrm{OH}$-bearing material. This may be the case for the relatively young Rheasilvia basin and for Marcia crater, where we do not see the hydration band. We speculate that the Marcia impact event destroyed $\mathrm{OH}$ rich material in a surficial or shallow crustal layer of dark material in the surface, and that it was the heat from that event that led to the devolatilization of the hydrated materials, thus forming the pitted terrain.

Seven areas of the smooth unit were mapped in and around Marcia and Calpurnia. Like the pitted terrain, the smooth unit is noted by its relatively lightly cratered surface at the tens of meters scale. The unit boundaries range from distinct to muted. Smooth material is found in topographic lows on the northern rim of Marcia. The unit also occurs within Marcia on the elevated bench in the southern part of the crater floor, which is separated from the rest of the floor by a scarp. This region of the smooth unit also contains lobate morphologies interpreted to be flows. The smooth unit that occurs on Calpurnia's floor and also has hummocky to lobate features suggestive of flow. We agree with Denevi et al. (2012) that the smooth units within Marcia and Calpurnia could be impact melt deposits that moved downhill following the local topography. The smooth units on the north rim of Marcia could also be impact melts, or alternatively accumulations of fine-grained materials deposited in local topographic lows by mass movement. In general, impact melts are rare on Vesta because of the low impact velocities (Marchi et al., 2013).

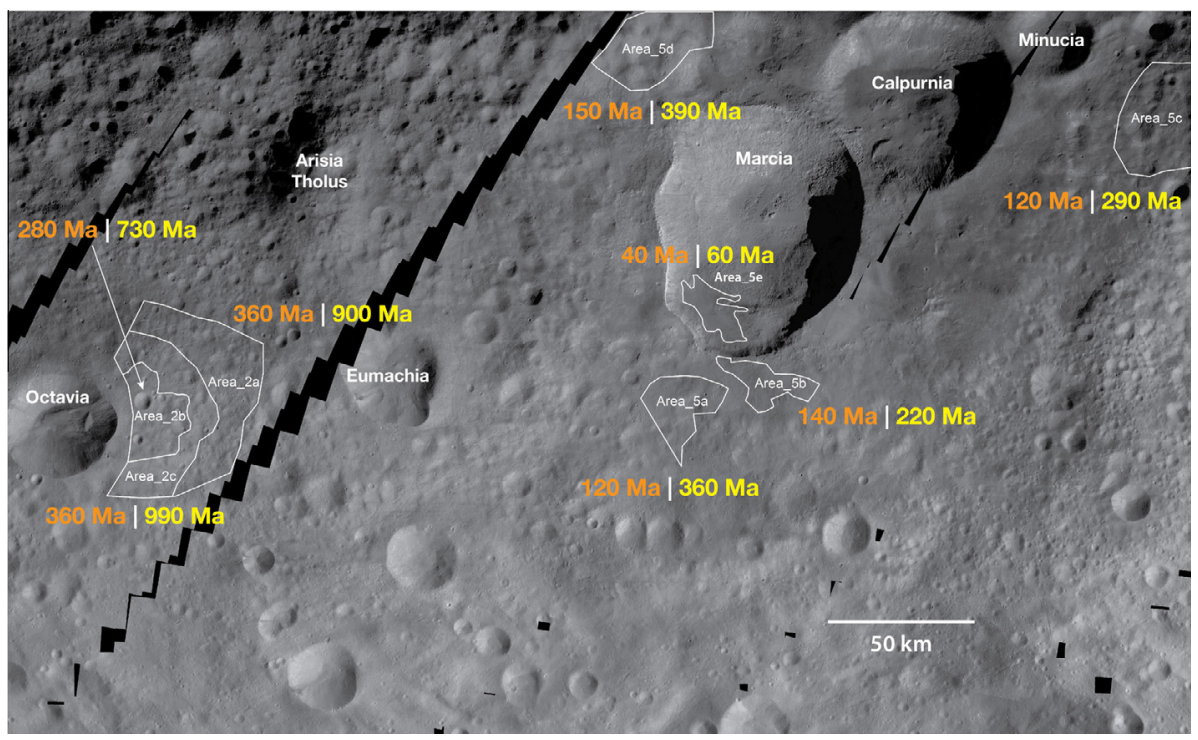

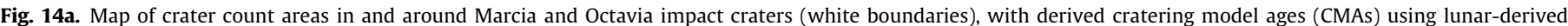

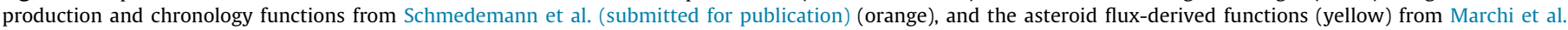

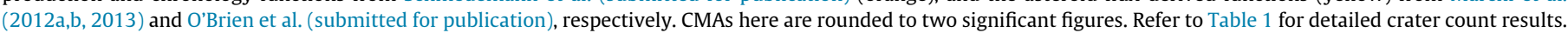



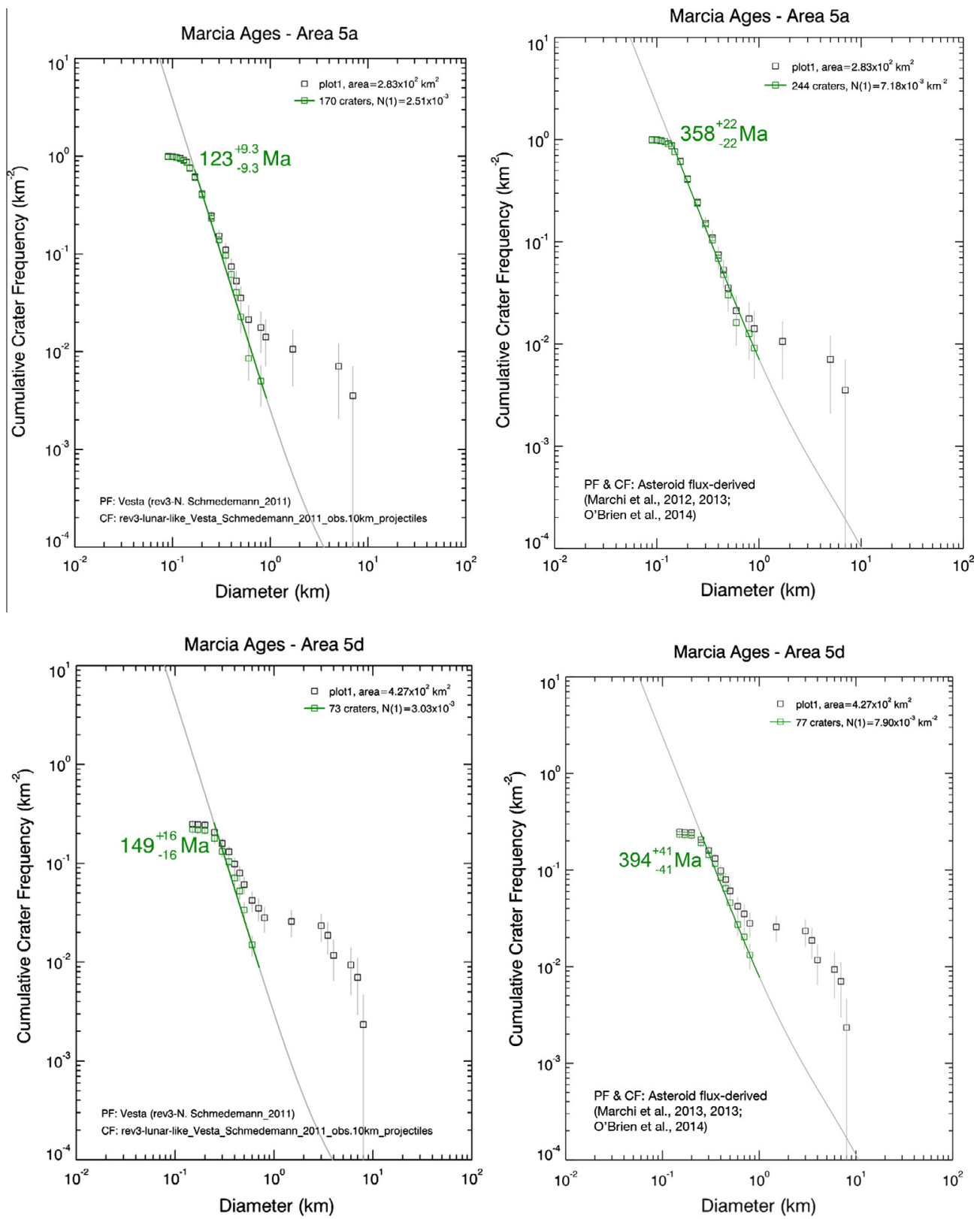

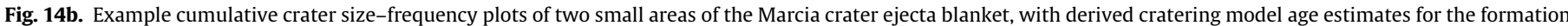

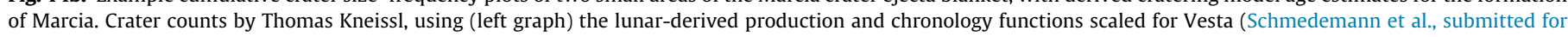

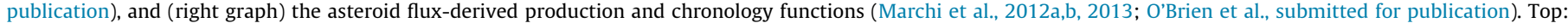
Area 5a. Bottom: Area 5d.

The FC false color ratio images show that the pitted terrain and smooth terrain units have a distinctive color signature (graybrown) compared to the Marcia and Calpurnia crater wall units (yellow-green to purple), which we call the bright crater unit and the crater wall unit. In Marcia, the bright crater unit has a relatively higher albedo with more distinct and less weathered alcoves, linear chains of outcrops, and boulders and debris accumulations at the tens of meters scale than the crater wall material in Calpurnia. In Calpurnia, the crater wall material has a relatively lower albedo and more weathered appearance, and consists of ridges, alcoves, and debris accumulations that deposit material on the (considerably less) pitted crater floor. We hypothesize, based on spectral processing of FC images, that there could have been an earlier, larger impact structure that underlies Marcia and Calpurnia (Fig. 9) that may have disrupted and overturned the vestan crust, thus altering the composition and texture of the surface impacted during the Marcia and Calpurnia events. Although we observe a smaller, degraded basin just to the west of Marcia in the topography data (Aricia Tholus may be part of its western rim), this putative larger impact structure is not visible in the DTM. This putative larger old structure would have had twice the diameter of Marcia, if traced further to the west. Nevertheless, the map units within Marcia and Calpurnia show distinct albedo variations in FC monochrome images, including very bright and very dark patches. Although we observe outcrops of the bright crater unit superposing the crater wall unit, what is not clear is the time interval between the Calpurnia and Marcia impact events. As mentioned earlier, the SW rim of Marcia displays outcrops of fresh bright material overlying a localized layer of dark material, which is in the process of being eroded from the crater wall (McCord et al., 2012). 

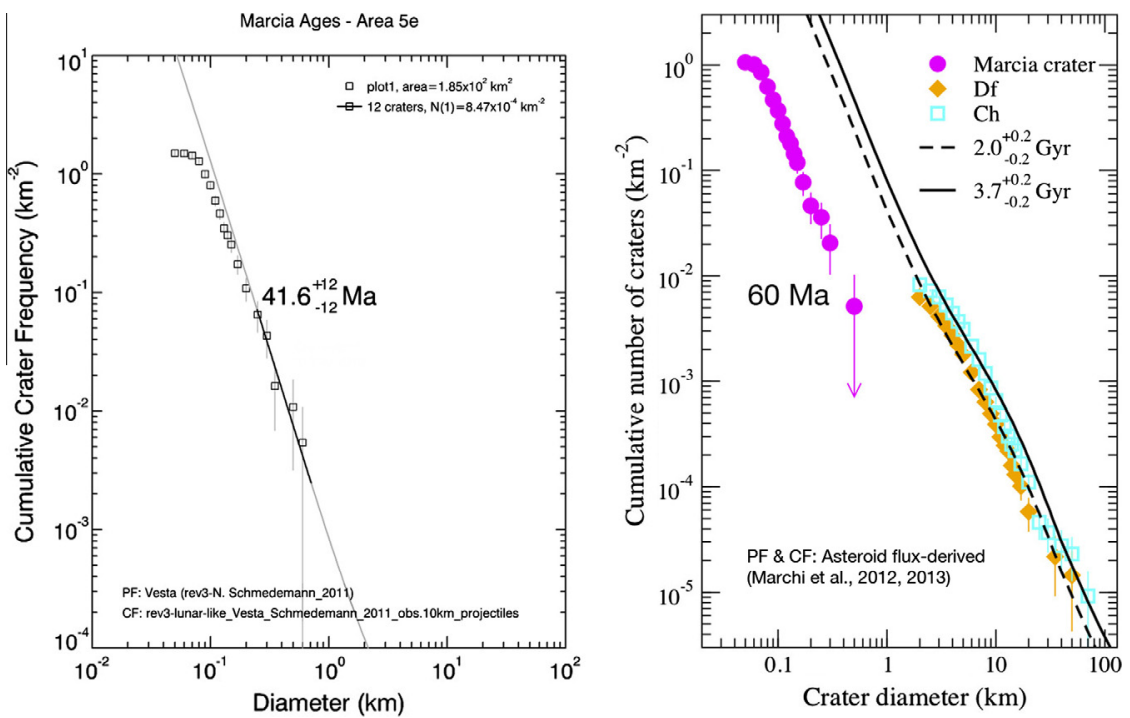

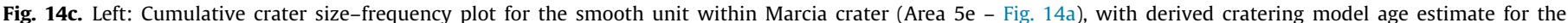

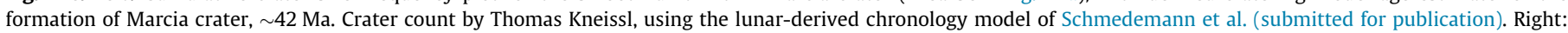

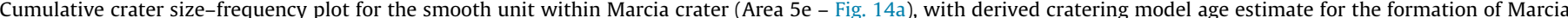

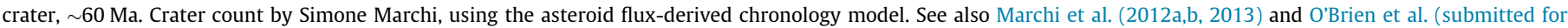
publication).
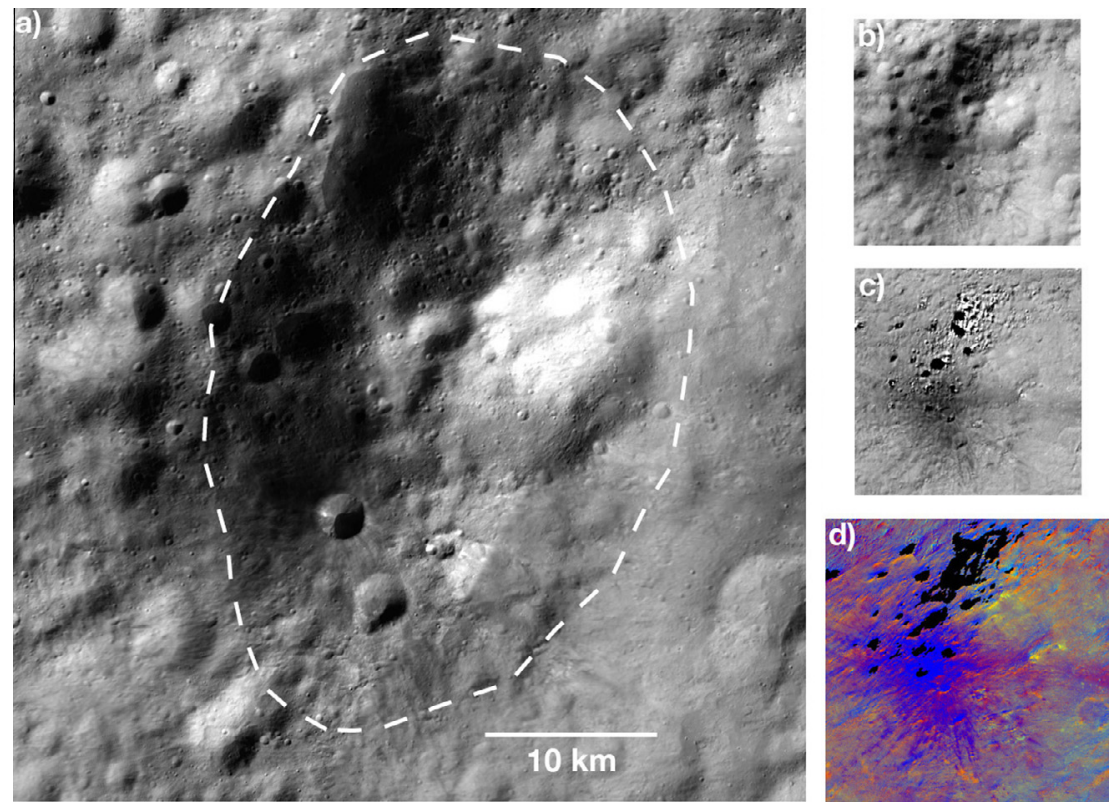

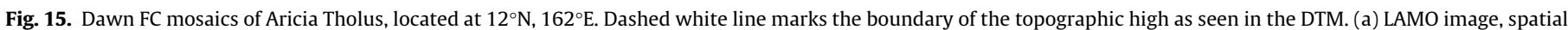

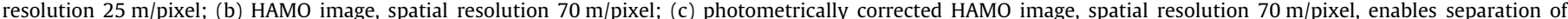

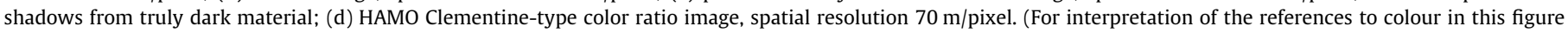
legend, the reader is referred to the web version of this article.)

The ejecta surrounding these craters is variable in terms of albedo, color and morphology, which we mapped as a crater ejecta unit underlying localized patches of bright and dark lobate units. This variability might suggest a complexity indicative of intermixed crustal material and various ejecta materials from the Marcia, Calpurnia, and Minucia impacts. The eastern part of the ejecta, between the crater rims and the cratered highland unit making up Vestalia Terra, has a very low albedo in monochrome images and a purple color in the color ratio images. We mapped this as a dark lobate unit. The VIR spectral data indicate that this unit is characterized by lower reflectance in the visible and near infrared and shallower pyroxene band depths. These properties could indicate the presence of opaque minerals or material that was altered by impact heating. Some of the darkest sections not only have a hummocky surface consistent with cratered terrain covered by impact ejecta, but also have smoother, more clearly-defined lobes that might suggest localized patches of darker impact melts mixed with the ejecta. The surface of the smoother areas containing small craters we interpret as a high porosity surface and a low velocity deposition of the material.

The western part of the ejecta generally has a relatively higher albedo and is more diverse than the eastern part. The ejecta west of 
Marcia and Calpurnia is characterized by a hummocky surface with localized patches of both bright and dark lobate units, and a higher abundance of older crater rims showing through the ejecta. The color ratio images show many small high albedo spots consistent with fresh impact craters (Reddy et al., 2010), which may have resulted from secondary impacts from the Marcia impact event. There are also several smaller patches of low albedo materials, including a distinctive dark-rayed crater located at $14^{\circ} \mathrm{N}, 180^{\circ}$, now named Laeta. We interpret this crater (Fig. 10) either as having excavated a darker layer underneath bright Marcia ejecta, or was produced by a dark impactor. If the former, we hypothesize that this is part of a regional dark layer also exposed in the western rim of Marcia (Fig. 11). We examined VIR data for four dark material regions in the northern part of this quadrangle (Fig. 12), and we determined that they are all are spectrally similar with very shallow pyroxenes bands (Fig. 13). This result suggests that all of the dark materials in this quadrangle have the same composition.

We performed crater counts on several areas of the Marcia crater floor and ejecta blanket (Figs. 14a and 14b, Table 1) to constrain the formation age of Marcia. Using the lunar-derived chronology model (Schmedemann et al., submitted for publication), a cratering model age of $\sim 40 \mathrm{Ma}$ is derived for the smooth unit on the elevated bench within the southern floor of the Marcia (that we interpret as impact melt: see also Denevi et al., 2012), and an age of 120150 Ma for several parts of the ejecta blanket. Using the asteroid flux-based chronology (Marchi et al., 2012a,b, 2013; O'Brien et al., submitted for publication), we obtained a cratering model age of $\sim 60$ Ma for the smooth unit on the Marcia floor, an age of $\sim 200$ Ma for the unit 5a on the ejecta blanket, and ages of 290$390 \mathrm{Ma}$ for other parts of the ejecta blanket (Fig. 14c). Impact processes usually deposit excavated material in the ejecta and on the crater floor at the same time. However in Marcia crater the ages of these geological units differ significantly, which requires an explanation.

There is a difference in opinion among the coauthors as to the cause of this age difference. Some coauthors (DAW, SM) think that different mechanical properties of the putative melt material vs. the ejecta material and their ability to preserve small craters are the major source of the differences in the age determination between these units. A biased number of larger craters or the masking of smaller craters by erosional processes drive the cratering model ages to older age values. One of us (S. Marchi) did a test on the crater count of Marcia ejecta area 5a, and found that using a hard rock scaling law and a material strength of $4 \times 10^{7}$ dyne/ $\mathrm{cm}^{2}$ resulted in the same cratering model age as that found for the Marcia floor smooth unit, $60 \mathrm{Ma}$ (that was derived using a strength of $2 \times 10^{8}$ dyne $/ \mathrm{cm}^{2}$, which is typical of hard rocks). Such variations in target properties between ejecta and impact melt, i.e., ejecta is composed of looser material than melted material, have been found to influence crater size-frequency distributions at small $(\leqslant 1 \mathrm{~km})$ crater sizes on the Moon (e.g., van der Bogert et al., 2010; van der Bogert et al., 2013a,b; Hiesinger et al., 2012).

Other coauthors (TK, NS) suggest that the smooth unit on the elevated bench in the floor of Marcia crater is not a impact melt, but material emplaced during a resurfacing event between $\sim 25 \mathrm{Ma}$ (resurfacing age in Marcia ejecta area 5b, closest to the crater wall) and $40 \mathrm{Ma}$ (age of the smooth unit). This resurfacing event could have been caused by gravity-driven mass wasting related to collapse of the south rim of the crater that formed the elevated bench, perhaps caused by seismic shaking from another impact event or slow devolatilization in the ejecta. In this scenario the crater counts of the ejecta blanket ( $\sim 120-150 \mathrm{Ma})$ reflect the true formation age of Marcia. Other factors that might contribute to the difference in ages between the putative melt and ejecta units include diffuse secondary cratering on the ejecta blanket, or subsequent resurfacing by some other process (e.g., downslope move- ment of fine-grained material because of seismic shaking from impacts).

More detailed study of crater statistics in several of Marcia crater's geologic units is currently underway. At the time of this writing, for clarity and consistency we use the $\sim 40-60$ Ma age of the putative impact melts as the formation age of Marcia crater. Readers are encouraged to check later Dawn Team publications on Marcia crater for updated age estimates. Although there is considerable spread in age estimates for Marcia's smooth and ejecta units ( $\sim 40$ $60 \mathrm{Ma}$ for smooth material, $120-390 \mathrm{Ma}$ for the ejecta), nevertheless these ages are the youngest for Vesta's large $(>25 \mathrm{~km}$ diameter) craters. Thus, we propose that the Marcia impact event marks a major time-stratigraphic horizon on Vesta, and that the geologic units related to the Marcia event be referred to as the Marcia Formation (Fig. 6).

\subsubsection{Aricia Tholus}

Aricia Tholus is located at $12.1^{\circ} \mathrm{N}, 161.8^{\circ} \mathrm{E}$, and was recognized in Dawn FC Approach images as a $42.5 \mathrm{~km}$ long (N-S), $28 \mathrm{~km}$ wide (E-W) topographic high topped by a low albedo feature within the northern cratered terrain. It was originally suggested to be a putative ancient vestan volcano (Williams et al., 2011), or perhaps exposure of a volcanic dike. However, through study of higher-resolution images it became clear that the low albedo feature on Aricia Tholus is caused by a superposed dark-rayed impact crater; subsequent study of photometrically corrected FC and VIR data demonstrated that part of the feature is due to shadows, and that the dark-rayed crater is the only inherently dark material on Aricia Tholus (Fig. 15). This dark-rayed crater stands out in FC color ratio images, with a purple color similar to the darkest part of the Marcia ejecta. Also in this case, the VIR data show that the pyroxene band depths are reduced with respect to the surrounding terrains, while the band centers do not show major differences in the position. VIR spectral data indicate that this material has a mineralogy similar to the neighboring terrains, but that the reflectance and the shallow bands of the dark material could be indicative of opaque minerals or impact processed material. However, the dark material on Aricia Tholus shows the presence of the $\mathrm{OH}$ absorption. We note that other studies (McCord et al., 2012; Reddy et al., 2012b) suggest that Vesta's dark material is exogenic, perhaps derived from carbonaceous chondritic impactors that accreted from primitive aster-

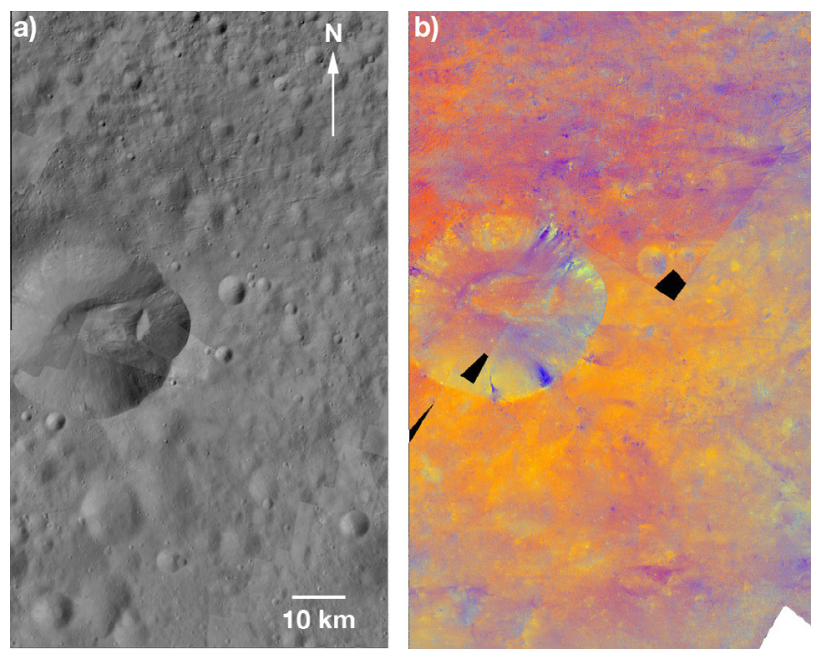

Fig. 16. Dawn FC mosaics of Octavia crater, located at $3.3^{\circ} \mathrm{S}, 147^{\circ} \mathrm{E}$. (a) LAMO image, spatial resolution $25 \mathrm{~m} /$ pixel; (b) HAMO false color ratio image, spatial resolution $70 \mathrm{~m} /$ pixel. The extent of the diffuse deposit is more clearly visible in the color ratio mosaic. (For interpretation of the references to colour in this figure legend, the reader is referred to the web version of this article.) 

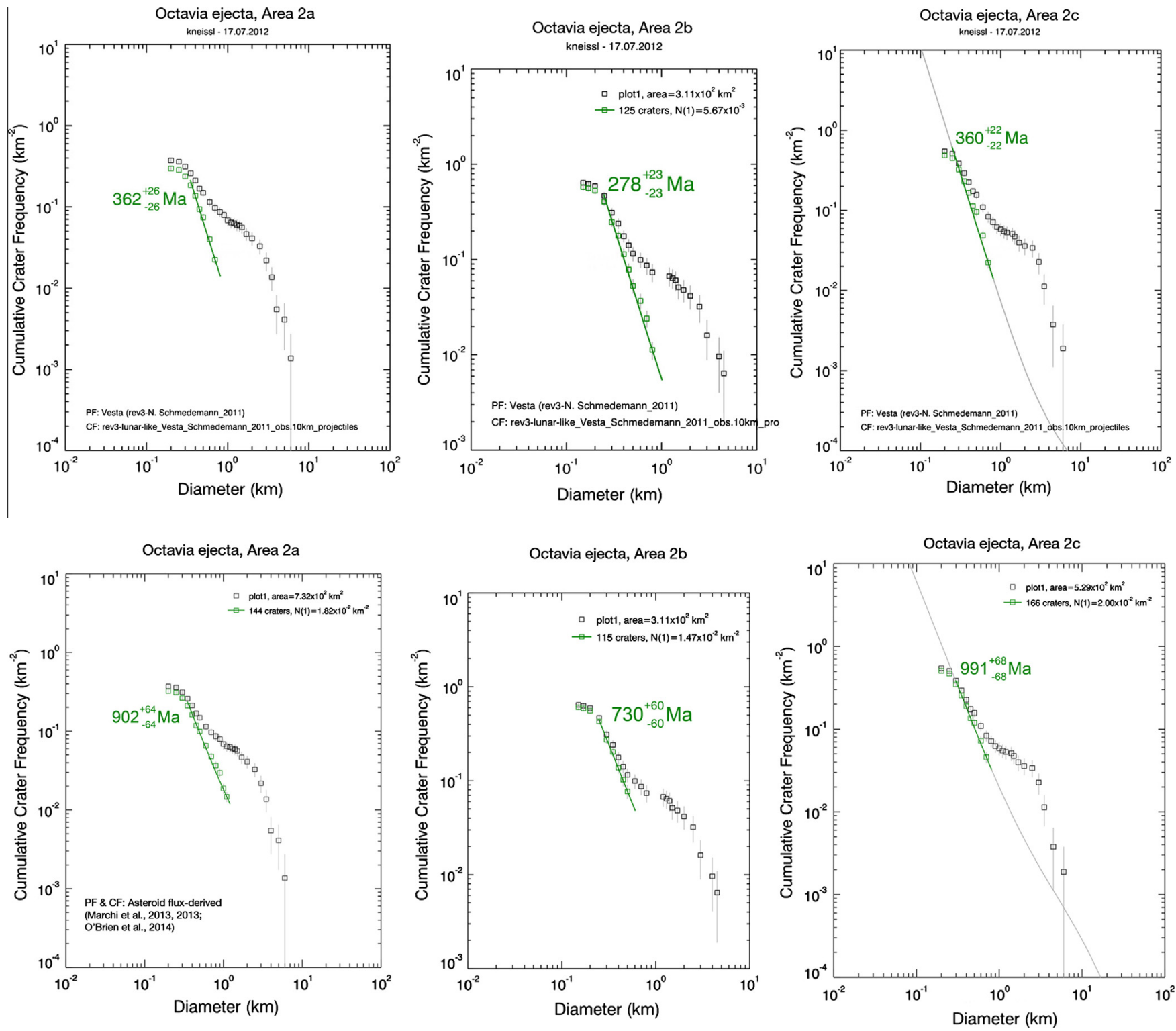

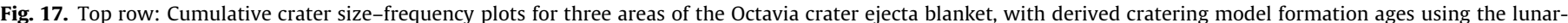

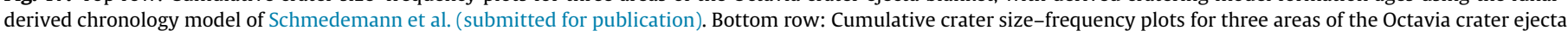

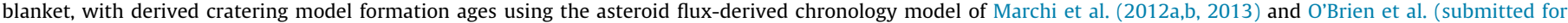
publication). All counts by Thomas Kneissl.

oids that are common in the Main Belt (see also Reddy et al., 2012b; De Sanctis et al., 2012b). Dark, carbonaceous chondrite clasts containing hydrated phases in their matrices are commonly found in howardite meteorites, which are regolith breccias from Vesta (Gounelle et al., 2003; Zolensky et al., 1996). Furthermore, the topography east of Aricia Tholus (Fig. 2) shows a subdued, circular low, which we interpret as an ancient impact basin. We interpret this result, along with the lack of any other evidence of a volcanic origin, to suggest that Aricia Tholus is best interpreted as an impact-sculpted fragment of an ancient impact basin rim or ejecta accumulation, with the superposed dark-rayed crater. However, there is no additional evidence to support or refute the dike hypothesis.

\subsubsection{Octavia crater}

The impact crater Octavia, $28 \mathrm{~km}$ diameter, is located on the western border of this quadrangle, and is one of two craters on Vesta (cf., Oppia: Le Corre et al., 2013; Garry et al., 2014) that has a diffuse mantle that surrounds the crater, appearing dark in FC monochrome images and bright orange in the FC false color ratio images (Fig. 16). The distribution of this diffuse mantling unit is not symmetrical around the crater, but rather extends $\sim 190 \mathrm{~km}$ to the west-northwest (Le Corre et al., 2013) and into the Av-7 Lucaria quadrangle (Schäfer et al., 2014). To date, FC color and VIR data analysis has not resulted in a specific mineralogical composition of this diffuse mantling material. It has a strong $2.8 \mathrm{~mm}$-absorption indicative of pyroxene, but no other diagnostic features of particular mineral compositions have been detected. Le Corre et al. (2013) found from comparison of FC color and VIR data to laboratory spectra of HED meteorites that this material most closely resembles howardite mixed with impact melt, and they suggested the Octavia impact may be excavating Veneneia ejecta as a possible source of the melt. We performed crater counts of parts of the Octavia ejecta blanket, and our results provide a model age of formation of $\sim 280$ $360 \mathrm{Ma}$ using the lunar-derived chronology and $\sim 730-990 \mathrm{Ma}$ using the asteroid flux-derived chronology (Fig. 17). Thus, Octavia 
is older than Marcia crater (consistent with its greater degree of degradation compared to Marcia) but is likely younger than Rheasilvia (Marchi et al., 2012a,b). Octavia does preserve a sharp rim on its south and east sides, and the relatively well-defined massmovement deposit on its interior.

\section{Geologic history of Marcia quadrangle}

The geologic history of Marcia quadrangle is outlined graphically in the Correlation of Map Units (Fig. 6). After Vesta's formation the crust crystallized from a magma ocean and was bombarded by impacts, forming various cratered highlands units, possibly including old craters such as Minucia. The Veneneia and Rheasilvia impacts at the south pole disrupted almost half of Vesta, deposited ejecta into the northern latitudes, and led to the formation of the Divalia Fossae Formation in the equatorial region and the Rheasilvia Formation within the south polar basins. Units interpreted to be mass wasting materials then formed as either ejecta or debris accumulated in crater floors. The Octavia impact event occurred $\sim 280-990 \mathrm{Ma}$ (depending on chronology system used), after Rheasilvia, depositing its unusual diffuse mantle to the west-northwest. Sometime prior to the Marcia event Calpurnia crater formed. The Marcia impact occurred ( 40-60 Ma based on crater floor smooth unit or $\sim 120-390$ Ma based on ejecta blanket, both depending upon chronology used), disrupting dark material in this quadrant and exposing bright ejecta units and creating the pitted terrain and smooth units on its floor and rim. The youngest features in this quadrangle are the various dark-rayed crater units superposed on Aricia Tholus and the Marcia ejecta, and bright-rayed crater (now named Flavola) superposed on the Veneneia rim region.

Our geologic mapping of the Av-8 Marcia quadrangle has shown the extent to which relatively young impact events have modified the surface of Vesta. First, the young, $68 \mathrm{~km}$ by $58 \mathrm{~km}$ Marcia crater disrupted the dark material exposed on Vesta's equatorial terrain west of Vestalia Terra, and exposed fresh, bright material with strong pyroxene absorptions probably associated with Vesta's basaltic crust. The stratigraphy around Marcia clearly shows the anti-correlation of bright, unweathered material with the dark material containing strong $\mathrm{OH}$ and $\mathrm{H}$ signatures in the VIR and GRaND data. Second, the small dark-rayed crater atop Aricia Tholus has the lowest albedo of all of features on Vesta. This observation suggests that this dark-rayed crater is the least mixed with other vestan crustal material, and therefore may be one of the youngest features on the surface. Compositionally, all of the dark materials exposed by both large and small impact events in this quadrangle have compositions consistent with all of the other dark materials observed elsewhere on Vesta, which have a high $\mathrm{OH}$ signature consistent with delivery from carbonaceous chondrite-rich material (McCord et al., 2012; Reddy et al., 2012b; De Sanctis et al., 2012b). Third, although the exact composition of the diffuse unit around the $\sim 280-990 \mathrm{Ma}$ (depending on chronology used) Octavia crater remains unclear, the presence of this diffuse, putative howardite + impact melt unit (Le Corre et al., 2013) around Octavia demonstrates that a variety of impactors struck Vesta over its history. Clearly impactors of a variety of compositions have struck Vesta's surface even into geologically recent times.

Additional study of the geologic units in the Marcia quadrangle would elucidate outstanding questions identified from our mapping. In particular, further work needs to be done to assess the ages and compositions of our map units, particularly identifying the abundances of howarditic versus eucritic material, and spectral unmixing studies to assess the mineralogy of the dark material. Detailed mapping of the Marcia crater wall and floor units could elucidate further information about the role of volatiles in the formation of features in these units. Also, analysis of the spectra of all bright-rayed craters on Vesta should be done to identify whether they have a consistent anti-correlation with $\mathrm{H}$ and $\mathrm{OH}$ signatures. Finally, identification of the compositional nature of the dark diffuse mantles around Octavia and Oppia craters (Garry et al., 2014) should be attempted.

\section{Conclusions}

Geologic mapping has illuminated the geologic history of the Marcia quadrangle of Vesta. In juxtaposition to the ancient cratered highlands and the large areas affected by the Veneneia and Rheasilvia impact events billions of years ago, the Marcia quadrangle is dominated by the formation of younger, larger $(>25 \mathrm{~km}) \mathrm{im}$ pacts. In particular, the event that formed Marcia crater disrupted the relatively large region of dark, hydrated material found in this hemisphere of Vesta, exposing both buried dark material and fresh, bright material with its strong pyroxene absorptions consistent with Vesta's eucritic crust. Because of the widespread distribution of its ejecta and the relatively young model ages compared to Vesta's largest craters, we infer that the Marcia impact event marks a major time-stratigraphic horizon in Vesta's geologic history after the Rheasilvia impact, with only much smaller rayed craters marking younger events. Future work should focus on detailed study of the VIR data to access compositional differences that can be correlated with the major geologic terrains on Vesta as revealed by geologic mapping, which would further elucidate the evolution of Vesta's crust and how it has been affected by impact events and space weathering.

\section{Acknowledgments}

The authors thank James Skinner, Wesley Patterson, and editor David Blewett for productive and helpful reviews. The authors also thank the NASA Dawn Science and Flight Teams at the Jet Propulsion Laboratory for their tireless work that enabled the successful Vesta encounter, and the instrument teams at the Max Planck Institute, the German Aerospace Center (DLR), the Italian National Institute of Astrophysics (INAF), and the Planetary Science Institute for collecting and processing the data that enabled this study. DAW was funded through Grant No. NNX10AR24G from the NASA Dawn at Vesta Participating Scientists Program. The VIR Team is funded by the Italian Space Agency (ASI) through Grant No. I/004/12/0.

\section{Appendix A. Supplementary material}

Supplementary data associated with this article can be found, in the online version, at http://dx.doi.org/10.1016/j.icarus. 2014.01.033.

\section{References}

Abramov, O., 2006. Impact-induced Hydrothermal Activity on Earth and Mars. Ph.D. Thesis, University of Arizona.

Boyce, J.M., Wilson, L., Mouginis-Mark, P.J., Hamilton, C.W., Tornabene, L.L., 2012 Origin of small pits in martian impact craters. Icarus 221, 262-275.

Buczkowski, D.L. et al., 2012. Large-scale troughs on Vesta: A signature of planetary tectonics. Geophys. Res. Lett. 39, L18205. http://dx.doi.org/10.1029/ 2012GL052959.

De Sanctis, M.C. et al., 2012b. Detection of widespread hydrated materials on Vesta by the VIR imaging spectrometer on board the Dawn mission. Astrophys. J. 758, L36. http://dx.doi.org/10.1088/2041-8205/758/2/L36.

Denevi, B. et al., 2012. Pitted terrain on Vesta and Implications for the Presence of Volatiles. Science 338, 246-249.

Garry, W.B. et al., 2014. The Geology of the oppia quadrangle of Asteroid (4) Vesta: Determining a relative stratigraphy and establishing a relative geologic timescale through geologic mapping. Icarus, submitted for publication. 
Gounelle, M., Zolensky, M.E., Liou, J.-C., Bland, P.A., Alard, O., 2003. Mineralogy of carbonaceous chondritic microclasts in howardites: Identification of $\mathrm{C} 2$ fossil micrometeorites. Geochim. Cosmochim. Acta 67, 507-527.

Hawke, B.R., Bell, J.F., 1981. Remote sensing studies of lunar dark-halo impact craters: Preliminary results and implications for early volcanism. Proc. Lunar Sci. Conf. 12, 665-678.

Hiesinger, H., van der Bogert, C.H., Pasckert, J.H., Funcke, L., Giacomini, L., Ostrach, L.R., Robinson, M.S., 2012. How old are young lunar craters? J. Geophys. Res. 117, E00H10. http://dx.doi.org/10.1029/2011JE003935.

Jaumann, R. et al., 2012. Vesta's shape and morphology. Science 336, 687-690.

Krohn, K. et al., 2014. Mass movement on Vesta at steep scarps and crater rims. Icarus, accepted for publication.

Le Corre, L. et al., 2013. Olivine or impact melt: Nature of the "orange" material on Vesta from Dawn. Icarus 226, 1568-1594.

Marchi, S. et al., 2012a. The cratering history of Asteroid (21) Lutetia. Planet. Space Sci. 66, 87-95.

Marchi, S. et al., 2012b. The violent collisional history of Asteroid 4 Vesta. Science 336, 690-694.

Marchi, S. et al., 2013. High-velocity collisions from the lunar cataclysm recorded in asteroidal meteorites. Nat. Geosci. 6, 303-307.

McCord, T.B. et al., 2012. Dark material on Vesta from the infall of carbonaceous volatile-rich material. Nature 491, 83-86.

O'Brien, D.P. et al., submitted for publication. Constraining the cratering chronology of Vesta, Planet. Space Sci.

Prettyman, T.H. et al., 2012. Elemental mapping by Dawn reveals exogenic $\mathrm{H}$ in Vesta's regolith. Science 338, 242-246.

Preusker, F. et al., 2012. Topography of Vesta from Dawn FC Stereo Images. European Planetary Science Congress, vol. 7 (Abstract \#428).

Reddy, V., Gaffey, M.J., Kelley, M.S., Nathues, A., Li, J.-Y., Yarbrough, R., 2010. Compositional heterogeneity of Asteroid 4 Vesta's Southern Hemisphere: Implications for the Dawn mission. Icarus 210, 693-706.

Reddy, V. et al., 2012a. Color and albedo heterogeneity of Vesta from Dawn. Science 336, 700-704.

Reddy, V. et al., 2012b. Delivery of dark material to Vesta via carbonaceous chondritic impacts. Icarus 221, 544-559.

Roatsch, T. et al., 2012. High resolution Vesta High Altitude Mapping Orbit (HAMO) Atlas derived from Dawn framing camera images. Planet. Space Sci. 73, 283286.
Ruesch, O. et al., 2014. Geologic map of the northern hemisphere of Vesta based on Dawn Framing Camera (FC) images. Icarus, in press, http://dx.doi.org/10.1016/ j.icarus.2014.01.035.

Russell, C.T. et al., 2012. Dawn at Vesta: Testing the protoplanetary paradigm. Science 336, 684-686.

Schäfer, M. et al., 2014. Imprint of the Rheasilvia impact on Vesta - Geologic mapping of quadrangles Gegania and Lucaria. Icarus, submitted for publication.

Schmedemann, N. et al., submitted for publication. The cratering record, chronology and surface ages of (4) Vesta in comparison to smaller asteroids and ages of HED meteorites. Planet. Space Sci.

Scully, J.E.C. et al., 2014. Saturnalia Fossa group of Fossae and additional structures in Vesta's Northern Hemisphere. Icarus, in press, http://dx.doi.org/10.1016/ j.icarus.2014.01.013.

Thomas, P.C., Binzel, R.P., Gaffey, M.J., Zellner, B.H., Storrs, A.D., Wells, E.N., 1997b. Vesta: Spin pole, size and shape from HST images. Icarus 128, 88-94.

Tornabene, L.L. et al., 2012. Widespread crater-related pitted materials on Mars: Further evidence for the role of target volatiles during the impact process. Icarus 220, 348-368.

Van der Bogert, C.H. et al., 2010. Discrepancies between crater size-frequency distributions on ejecta and impact melt pools at lunar craters: An effect of different target properties? 41st Lunar and Planetary Science Conference, Abstract \#2165. Lunar and Planetary Institute, Houston, TX.

Van der Bogert, C.H., Hiesinger, H., Krüger, T., McEwen, A.S., Dundas, C., 2013b. New evidence for target property influence on crater size-frequency distributions. Lunar Planet. Sci. XLIV. Abstract \#1962.

Vincent, J.-B. et al., 2014. Crater depth-to-diameter distribution and surface properties of (4) Vesta. Planet. Space Sci. doi: http://dx.doi.org/10.1016/ j.pss.2013.09.003 (in press).

Williams, D.A. et al., 2011. Mapping Vesta equatorial quadrangle V-10EW: Identification of dark (Volcanic?) features. Eos (Suppl.), Trans. American Geophysical Union (Fall). Abstract P36-\#\#\#\#.

Williams, D.A., Yingst, R.A., Garry, W.B., 2014. Introduction: The geologic mapping of Vesta. Icarus, in press, http://dx.doi.org/10.1016/j.icarus.2014.03.001.

Yingst, R.A. et al., 2014. Geologic mapping of Vesta. Planet. Space Sci., in press.

Zolensky, M.E., Weisberg, M.K., Buchanan, P.C., Mittlefehldt, D.W., 1996. Mineralogy of carbonaceous chondrite clasts in HED achondrites and the Moon. Meteorit. Planet. Sci. 31, 518-537. 